\title{
Fianzas, avales y demás garantías en la legislación de Régimen Local
}

\author{
José P. Viñas Bosquet \\ Interventor-Tesorero de Administración Local \\ Auditor de cuentas (IACJCE)
}

\begin{abstract}
Sumario: 1. INTRODUCCIÓN. 2. ANTECEDENTES LEGALES. 3. ESTUDIO DE LOS MEDIOS DE GARANTÍA EN LA ACTUALIDAD. 3.1. Distinción conceptual. 3.2. Clasificación. 3.2.A. Garantías reales. 3.2.B. Garantías personales. 3.3. Contrato de fianza. 3.4. Aval bancario. 3.5. Seguro de caución. 4. REQUISITOS FORMALES: GARANTÍAS A PRIMERA DEMANDA. 5. GARANTÍAS REALES. 5.1. Prenda de valores por anotaciones en cuenta. 5.2. La prenda de créditos. 6. ESTUDIO DE LAS GARANTÍAS NECESARIAS EN LA LCAP. 7. PARTICULARIDADES EN LA LEY DE HACIENDAS LOCALES. 8. GARANTÍAS POR ACTOS Y CONVENIOS URBANÍSTICOS. 9. ALGUNAS CONCLUSIONES.
\end{abstract}

\section{INTRODUCCIÓN}

La cada vez más compleja realidad económica en la que se desenvuelven los Ayuntamientos y Diputaciones, tanto en el ejercicio de competencias reguladoras o de desarrollo normativo, como en lo referente a aspectos puramente contractuales o convenidos, hace preciso que en muchas de estas actuaciones se deba exigir, de forma paralela a la ejecución de las mismas, la constitución de una garantía o caución que asegure el cumplimiento de lo acordado o, en su caso, resuelto por las entidades locales. Las formas en las que los administrados pueden garantizar ante los diversos entes públicos el cumplimiento de las distintas obligaciones son diferentes $\mathrm{y}$, en los últimos tiempos, dichos medios se encuentran en permanente renovación, ya que las figuras conocidas tradicionalmente se ven desbordadas por otras nuevas, más rutilantes y complejas, tanto en lo referente a su calificación jurídica, como a los efectos, jurídicos, económicos o patrimoniales, que despliegan.

Uno de los campos que no ha podido sustraerse a la complejidad de dichos cambios es el referente a las garantías propias de la contratación administrativa, donde se vienen introduciendo, con motivo de las diversas modificaciones legales a las que dicha legislación administrativa esta sometida, novedades importantes. Así, por ejemplo, podemos citar, tras la promulgación de la Ley de Contratos de las Administraciones Públicas, el desarrollo de la denominada garantía global, la exclusión de la garantía 
provisional, de forma obligatoria en ciertos aspectos de la contratación, la admisión del seguro de caución, o incluso la presentación de garantías, mediante la fórmula de anotaciones en cuenta ${ }^{1}$, aspectos todos ellos de gran trascendencia, y que en las relaciones habituales de las entidades locales es preciso conocer, por lo complejo e indeterminado, en muchos casos, de su regulación legal o reglamentaria.

A la par de lo anterior, se han producido en las paulatinas modificaciones de la Ley de Haciendas Locales ${ }^{2}$ cambios sustanciales en materia de revisión de actos tributarios, que, a su vez, han supuesto una importante reforma en el apartado de las cauciones necesarias, para la suspensión de la ejecutividad de los mismos. Por lo que, desde este aspecto concreto, resulta también conveniente analizar las garantías necesarias en dichos procedimientos, y que si bien, con finalidades sustancialmente distintas, a las anteriormente comentadas, como garantías requeridas en actuaciones, ante órganos y sujetos administrativos, quedan todas ellas sometidas al régimen jurídico propio de los entes locales.

Por otra parte, no podemos dejar de resaltar la importancia que últimamente esta tomando, dentro del estudio de las garantías, el aspecto contable de su registro y ello basado en el principio de que la contabilidad, como instrumento de información, debe tener la suficiente capacidad explicativa de los fenómenos que son objeto de su medición y representación. Así, dada la complejidad de algunas de estas figuras, desde esta disciplina se está realizando, también, un esfuerzo meritorio de análisis y comprensión de las mismas, para poder realizar su anotación, de la forma más correcta y relevante para los estados financieros y patrimoniales.

De cualquier manera, la importancia que presenta en la actualidad el estudio de las garantías necesarias en los procedimientos de gestión local viene determinado, de una parte, por la rapidez con la que se introducen nuevas figuras, o se realizan cambios y modificaciones sobre las ya conocidas, lo que nos ha movido al estudio de las mismas, por la importancia que entraña su calificación; al evaluar su adecuación y suficiencia, dado el riesgo implícito de quebranto o falencia que puedan presentar. Y, por

\footnotetext{
${ }^{1}$ Circunstancia ésta que, como veremos posteriormente, está expresamente recogida en el artículo 10 de la Ley 24/1988, de 28 de julio, del Mercado de Valores, y en cuya Exposición de Motivos ya se resalta la importancia de dicha novedad, que, a su vez y paulatinamente, provocaría una pérdida de importancia de los tradicionales títulos-valores.

2 En concreto, la Ley 50/1998, de Medidas Fiscales, Administrativas y de Orden Social, cuyo artículo 18.9. ${ }^{\circ}$, modifica la redacción del primitivo artículo 14 de la Ley Reguladora de las Haciendas Locales, sobre el recurso de reposición.
} 
otra parte, por la agilidad y premura que su tramitación y admisión requieren, puesto que deben realizarse, como mucho, en los propios plazos otorgados para los actos a los que deben servir, nota ésta, que se encuentra en abierta contraposición al extremado formalismo que requieren para su validez, y que hacen por tanto, que su estudio y conocimiento, sea hoy ciertamente significativo, justificando, también con ello, el presente trabajo.

Las dificultades y complejidad que venimos comentando, no deben considerarse una cuestión insustancial o baladí, pues su importancia ha sido resaltada incluso, en normas concretas, como, por ejemplo, en el ámbito tributario. Donde ha originado que la calificación previa de garantías, que en los Tribunales Económico-Administrativos venía siendo una competencia de los Servicios Jurídicos, adscritos a dichos Tribunales, haya pasado por el artículo 76.9 del RREA, del año 1996, a los órganos de recaudación de la Agencia Tributaria ${ }^{3}$, que incluso, en casos sumamente complejos, pueden pedir el informe concreto de peritos especializados y contratados externamente.

En conclusión, en el presente trabajo, pretendemos exclusivamente, de una parte, realizar una clasificación rápida y precisa de la tipología, así como de las innovaciones que, en materia de garantías, se vienen produciendo con mayor profundidad en el ámbito de disciplinas, como el Derecho mercantil o la Contabilidad Financiera, pero que, de alguna manera, se están traspasando al campo del Derecho administrativo, en donde se aprecia una escasez de estudios sobre esta cuestión.

Por otra parte, dada la extensión y complejidad de los medios posibles y a la vista de las limitaciones de exposición existentes en el presente trabajo, efectuaremos un breve repaso, dentro de las formas de garantía más conocidas y utilizadas en la actualidad, en el Derecho administrativo y, más en concreto, en el Régimen Local, de los requisitos formales y cualidades documentales, que la legislación exige para su plena validez.

Por último y a la vista de lo anterior, intentaremos analizar, dentro de las diversas reglamentaciones aplicables a los entes locales, dependiendo de la materia concreta en la que nos movamos, la posible existencia de $l i$ mitaciones legales a la admisión y validez de las mismas, ya que en cier-

\footnotetext{
${ }^{3}$ El mencionado artículo 76.9, del RD 391/1996, por el que se aprueba el Reglamento del Procedimiento de las Reclamaciones Económico Administrativas (en adelante RREA), establece: «El tribunal solicitará del órgano de recaudación a que se refiere el artículo 75.2 del reglamento, que informe sobre la idoneidad y suficiencia de las garantías ofrecidas, para lo cual será de aplicación lo establecido en el artículo 52.9 del Reglamento General de Recaudación» (en adelante RGR).
} 
REAL-2001, núm. 286-287. VIÑAS BOSQUET, JOSE P.. FIANZAS, AVALES Y DEMÁS GARANTí...

REAL 286-287 (MAYO-DICIEMBRE, 2001)

tos casos, es la propia legislación la que establece exclusiones o restricciones singulares a algunos medios o formas de garantía.

\section{ANTECEDENTES LEGALES}

Es sumamente interesante en el desarrollo de este trabajo y como punto de partida, conocer dentro de la legislación local que ha regulado la materia referente a fianzas y garantías, los antecedentes de la tan dispersa situación actual. Por lo menos, de aquellos que podríamos llamar, como precedentes inmediatos y que en algunos de los casos, aún están vigentes, como son los establecidos, en el Reglamento de Contratos del Estado de 25 de noviembre de 1975, así como aquellos otros, más lejanos, pero que, por ciertas circunstancias, aún perviven, siendo además específicos del Régimen Local ${ }^{4}$; me refiero, fundamentalmente, a los establecidos en el Texto Refundido la Ley de Régimen Local de 1955, así como a los Reglamentos de desarrollo de la misma, como son el Reglamento de Bienes de las Entidades Locales. Éste, rejuvenecido y adaptado, por Decreto $1372 / 1986$, de 13 de junio, o el Reglamento de Servicios de las Corporaciones Locales, aprobado por Decreto de 17 de junio de 1955, que consideramos sólo derogado en lo que no se oponga a la normativa vigente posterior, y que a pesar de las modificaciones y cambios introducidos en la legislación administrativa de carácter local, en parte, dicho texto se considera actualmente vigente ${ }^{5}$.

El análisis de la legislación precedente, a los efectos de este trabajo, es ilustrativo, por varios motivos. De una parte, podemos apreciar, de forma conjunta, la sistemática, posibilidades y medios reconocidos en el mismo, dado que la legislación del Régimen Local antecedente del actual, como veremos, formaba un «corpus normativo homogéneo» $\mathrm{y}$, de otra,

\footnotetext{
${ }^{4}$ En este punto no podemos dejar de comentar, la problemática permanente que suscita en las entidades locales, la aplicación de la legislación local, que se formula como una copia o clonación legal, del modelo estatal, y que si bien, puede resultar efectiva en el hacer cotidiano de la Administración del Estado, no resulta tan válido, aplicado a los entes locales. Circunstancia por demás, comentada desde todos los aspectos doctrinales, así por ejemplo, en aspectos Presupuestarios de los entes locales vide V. J. Arnau Bernia, Manual de Presupuestos de las Entidades Locales, ed. Marcial Pons, 1991. Y también, el magnífico «Los Interventores de la administración local y las funciones de control interno», Rev. de Hacienda local, n. ${ }^{\circ}$ 72, diciembre 1994. También en este sentido, más recientemente, se puede ver a nivel contable P. CABALLERo PAstor, Manual de Presupuestos y Contabilidad de los entes locales, ed. Comares, 2000, pp. 4 y ss.

5 Así se comenta por A. Ballesteros Fernández, en Contratos de las Administraciones públicas, ed. El Consultor, 1997, pp. 271 y ss. Un análisis más completo de la vigencia de dicho reglamento en F. Sosa Wagner, La gestión de los servicios públicos locales, ed. Civitas, 1999; y en J. L. Rivero Ysern, Manual de Derecho Local, ed. Civitas, 4. a edición, 1999.
} 
porque supone un recorrido ilustrativo, casi pedagógico, de los medios de garantías típicos y específicos, en el régimen local, que nos puede ilustrar sobre las posibilidades de la situación actual.

En materia de garantías, el Texto Refundido de la Ley de Régimen Local de 1955 (en adelante LRL) establecía la necesidad de prestar las mismas, en diversas ocasiones y por distintos motivos. Así, en materia de Hacienda Local, en el trámite de las reclamaciones y del recurso de reposición, contra actos de aplicación y efectividad de exacciones, según se establecía en el artículo 727 de la LRL y en el Reglamento de Haciendas Locales, de 4 de agosto de 1952 (RHL), materia ésta, en la que «sólo se admitían» las garantías que, a elección del reclamante, venían establecidas en el punto 7 de dicho artículo 727, cuales eran:

- El ingreso en efectivo en la Caja General de Depósitos, en la de la Corporación acreedora, o en el Banco de España, a disposición del Presidente.

- En depósito, en cualquiera de los establecimientos indicados, de títulos de Deuda Pública del Estado o de la Entidad Acreedora, y siempre por su «valor efectivo», sea cual fuere, su clase.

- Mediante fianza solidaría de un banco, a satisfacción de la autoridad u organismo correspondiente.

En casos muy cualificados y excepcionales, podían, sin embargo, las entidades locales acreedoras acordar, discrecionalmente y a instancia de parte, el aplazamiento de la exacción, sin prestación de garantía alguna, cuando el reclamante alegare y justificare en la solicitud la imposibilidad de prestarla 6 .

Como podemos apreciar, en el campo de las Haciendas Locales, de antiguo el mismo estaba legalmente limitado, en cuanto a los medios de garantía a presentar. Existiendo, por tanto un numerus clausus de los medios admisibles, siendo además las formas de las mismas, dado el tiempo en el que se promulgó dicho Reglamento, de una sencillez ilustrativa, incluso pedagógica, reduciéndose al depósito en metálico, la prenda de títulos del Estado o la Entidad Local y la fianza de Banco exclusivamente,

\footnotetext{
${ }^{6}$ Vemos en este artículo que la posibilidad de suspensión de la eficacia de los actos administrativos, sin necesidad de garantía, tiene en la hacienda local una larga tradición legal, si bien, con carácter excepcional. Así se incluyó inicialmente en la LHL, y en la actualidad, aun sin citarse expresamente, se sigue aplicando, en virtud de lo establecido en el artículo 14.I) de la misma y en el Reglamento de las Reclamaciones Económico-Administrativas.
} 
quedando además a satisfacción o conveniencia exclusiva de la Administración. Se limitaba pues, como vemos, la complejidad de la admisión y el análisis de su suficiencia y validez, circunstancias que no se dan en la actualidad ${ }^{7}$.

En materia de contratos, la legislación de Régimen Local anterior a la actual, venía recogida fundamentalmente, en el Reglamento de Contratación de las Corporaciones Locales, de 9 de enero de 1953 (en adelante, RCCL). En el mismo con una técnica depurada, así como por su intención pedagógica, se recogía en materia de garantías una regulación ordenada y sistemática de las mismas, bajo el título genérico de «Garantías de la Contratación», y que resumimos seguidamente.

«En toda subasta, concurso o concurso-subasta, y antes de la celebración de los mismos», decía el artículo 72 de dicho RCCL, «los licitadores deberán presentar garantía provisional, para asegurar a la Corporación que formalizará, en su caso, el contrato»; continuando el artículo 73 del mismo, que «En todo contrato sea del tipo que sea, excepto ventas al contado, será requisito indispensable que el adjudicatario establezca garantía suficiente, que asegure el cumplimiento de las estipulaciones y la efectividad de las responsabilidades que pudieran derivarse». En este sentido, carecían de eficacia los contratos en que dicha garantía no apareciese constituida reglamentariamente. Imponiendo incluso una obligación al Interventor de Fondos Municipal, que debía negarse al pago de cualquier cantidad al contratista que no hubiera constituido reglamentariamente, la garantía definitiva (art. 73.3 RCCL).

El artículo 75 de dicho Reglamento recogía de igual manera las formas o medios de prestar la misma, siendo admitidas las siguientes:

— En Metálico o en Valores Públicos.

— En créditos reconocidos y liquidados, por la Corporación contratante.

- Por Fianza personal.

- Mediante hipoteca y por último mediante retenciones del importe de las certificaciones de abono, al destajista.

\footnotetext{
${ }^{7}$ Sobre el laberinto jurídico actual, reiteradamente puesto de relieve, citar los trabajos de insignes catedráticos, vide Tomás Ramón Fernández, De la arbitrariedad del Legislador, ed. Civitas, 1999. E. GARCÍA DE EnTERRÍA, «Justicia y seguridad jurídica en un mundo de leyes desbocadas», ed. Civitas, 1999. También otros no menos ilustrativos, así, A. Vera Fernández Sanz, «Las dificultades actuales para el conocimiento cabal de las Leyes», Rev. El Consultor de los Ayuntamientos, n. ${ }^{\circ} 1$, enero 2000 , pp. 44 y ss.
} 
Detallando a continuación el RCCL las circunstancias particulares de cada tipo concreto de garantía. Así, los valores públicos admitidos en prenda, como forma de garantía, podrían constituirse en la Caja General de Depósitos o en sus sucursales o en la de la Entidad contratante. Debiendo ser valores emitidos exclusivamente por el Estado español, Entidad contratante, o establecimientos de crédito sostenidos por las mismas o Banco de Crédito Local. En cuanto a la valoración de los efectos públicos, éstos sí eran perpetuos o no amortizables, lo harían al valor de la última cotización, y sí eran amortizables se valorarían al nominal o a la par, siendo imprescindible para la constitución de la prenda, la presentación de la póliza o título de adquisición y propiedad de los mismos, incluso en caso de títulos al portador ${ }^{8}$.

En el caso de créditos contra la entidad local interesada, se podían aceptar como garantía, siempre que estén reconocidos y liquidados a favor de quienes la constituyan como licitadores, adjudicatarios o fiadores de los mismos. En el mismo sentido, el actual artículo 41.3 de la LCAP, si bien conforme comenta CALVO ROJAS ${ }^{9}$, la Sentencia del TS de 3 de enero de 1989 (Ar. 583) ha determinado «que la retención es operativa, únicamente en relación al contrato de que se trata, y no en relación a cualquier contrato pendiente, entre la Administración y el contratista».

La Fianza Personal sólo era admitida en el RCCL, para entidades de menos de 2.000 habitantes, y para pequeños importes y plazos menores a un año (se establecía una amplia limitación a esta modalidad), admitiendo exclusivamente, como fiador a un vecino de la localidad contribuyente, siendo en todo caso subsidiariamente responsables del buen fin de la misma, los concejales que la hubieran admitido, con carácter solidario, debiendo constituirse siempre ad solemnitatem o por escrito.

En el caso de venta de inmuebles a plazos, la garantía podrá consistir en hipoteca sobre los mismos inmuebles, que aseguren el pago de los plazos (art. 80 RCCL).

Por último, en las obras o destajos como modalidad de concierto directo, las garantías podrán consistir en la retención del tanto por ciento que se establezca, sobre el importe de las certificaciones de abono al con-

\footnotetext{
${ }^{8}$ Como podremos comprobar a lo largo de este trabajo, rige en materia de garantías un riguroso formalismo, que tiene carácter constitutivo, nota ésta, que como vemos, en este artículo del RCCL, no es reciente, y que proviene del Derecho Privado. Con ello queremos resaltar la expresión «imprescindible» para la válida constitución de la garantía.

${ }^{9}$ E. Calvo Rojas, en Derecho de los contratos públicos, AA.VV., ed. Praxis, 1995, p. 367.
} 
tratista, hasta cubrir la cuantía necesaria. Ésta puede considerarse una particularidad del régimen general de retención, detallado en el apartado anterior de créditos contra la entidad ${ }^{10}$.

En este punto resulta conveniente citar igualmente, aunque sólo a un nivel introductorio, puesto que, las veremos más adelante, las disposiciones contenidas en el Reglamento de Servicios de las Corporaciones Locales (RSCL), de 17 de junio de 1955. En el mismo, por ejemplo, en materia de gestión indirecta de servicios, en concreto en la gestión mediante concesión administrativa, se establecía (art. 125.3) «la necesidad de prestar garantía definitiva, para formalizar la concesión que otorgue el ente local». En este tipo de gestión de servicios mediante concesión, la dicción del artículo 116.1 del RSCL recoge que «serán nulas las concesiones que no se ajusten a las formalidades establecidas en el mismo»y y para lo no dispuesto expresamente en el RSCL, reenvía directamente al Reglamento de Contratos (RCCL), y en la actualidad a la legislación de Contratos de las Administraciones Públicas ${ }^{11}$.

En el mismo sentido, el Reglamento de Bienes de las Corporaciones Locales, aprobado por el RD 1372/1986, de 13 de junio, establece, por ejemplo, en sus artículos 87.3 y 90.1, la necesidad de prestar fianza o garantía provisional del 2 por 100 del valor del dominio público objeto de ocupación, y en su caso, del presupuesto de las obras que hubiesen de realizarse, o el 3 por 100 de dichos valores, como garantía definitiva, que deberá constituir el adjudicatario de la concesión de ocupación, en garantía de la correcta utilización del mismo. Conforme a los artículos 90.4, 92.1 y 112 del R. Bienes de las Corporaciones Locales, es subsidiariamente aplicable la legislación de Contratos, vigente para la Administración Local. En la actualidad LCAP, lo que nos obliga a examinar su evolución, para ir acercándonos al sistema que rige actualmente.

La legislación local comentada anteriormente debió con el cambio de los tiempos ir adaptándose a las nuevas formas que en materia de contratos se venían estableciendo. El primer envite fuerte lo supuso la introducción de la Ley de Contratos del Estado, según el Texto Articulado de 8 de

\footnotetext{
10 La Resolución de la IGAE de 6 de noviembre de 1996 señala que cuando se constituya la garantía mediante retención en el precio, los centros gestores, deberán expedir documento OK o similar, por el importe del contrato, incluyendo como descuento, además de los que les corresponda, el importe de la garantía definitiva.

11 Con F. Sosa Wagner, La Gestión..., pp. 127 y ss. Entendemos, que en cuanto a las garantías necesarias, del expediente de concesión de un servicio público, éstas vienen reguladas, en la actualidad, en la LCAP.
} 
abril de 1965, y la reglamentación de desarrollo, aprobada por el Decreto $3410 / 1975$, de 25 de noviembre (éste, en parte, todavía hoy vigente), en la cual, su artículo 112, dentro de un título único, destinado exclusivamente a «Fianzas y demás garantías en los Contratos del Estado», establecía los medios y formas de prestar las mismas, para contratar con la Administración estatal. De tal suerte, que se comprueba ya su carácter restrictivo, al limitar las posibilidades, en comparación a las fórmulas del Régimen Local, vistas anteriormente, pues para la garantía provisional únicamente se admitía la entrega en metálico, o el depósito en títulos de la Deuda Pública (estatal), ambos en la Caja General de Depósitos o bien mediante la figura del Aval. Novedosa fórmula, que posteriormente tendrá un importante desarrollo, en parte debido al propio Reglamento de Contratos, que le dio una estructura y tipología concreta, como forma de garantía, facilitando así su difusión por los intermediarios y oferentes de servicios, fundamentalmente, las entidades bancarias.

Sin entrar en una pormenorización, comentar algunas notas concretas y que denotan en esta materia dicho carácter restrictivo del RCE. Así, sólo se admitían como fianza provisional en el caso de valores (art. 343 RCE), «los que tuvieran concedido este beneficio por disposiciones del Gobierno y, en todo caso, los emitidos y avalados por el Estado, por el 2 por 100 del importe del presupuesto total.

Las Fianzas complementarias serían de hasta el 6 por 100 de los importe del presupuesto ${ }^{12}$, en los mismos términos y por los mismos medios, que las definitivas (Metálico, Títulos-Deuda y Aval) y junto con ésas, deberán responder de: Penalidades impuestas al contratista, del resarcimiento de los daños y de la incautación que pueda decretarse, en los casos de resolución del contrato, de acuerdo con lo establecido en el mismo o con carácter general, en la legislación del Estado.

La reglamentación del aval, incluida en los artículos 370 y siguientes del RCE, fue autorizada e introducida expresamente, como medio de garantía en la Administración Local, por el RD. 3046/1977, por el que se aprueba el texto articulado de Bases del Régimen Local de 1975, ya que, en su artículo $110.9{ }^{\text {a }}$, posibilitaba su utilización por los entes locales, como complemento a los medios de garantía ya regulados en los reglamentos de desarrollo de la Ley de Régimen Local.

\footnotetext{
12 Según informe de la Junta Consultiva de Contratación 99/1966, «la base para calcular las fianzas provisionales se establecía en el artículo $112 \mathrm{LCE}$, sobre el presupuesto de ejecución material, más los conceptos de beneficio industrial dirección y administración e imprevistos que le sean aplicables, o de otro modo, a la suma que el contratista estaría obligado a satisfacer, cuya base es igualmente aplicable en la fianza definitiva».
} 
Tras estos primeros apartados, sobre normativa reglamentaria específica de carácter local, y aplicación de normas estatales de forma directa a procedimientos locales y que nos ha servido para situarnos en el contexto actual del tema tratado, debemos continuar con la regulación legal vigente, fundamentalmente la establecida en la Ley de Bases del Régimen Local, de abril de 1985, así como en la otra Ley concreta del ámbito local, la Reguladora de las Haciendas Locales, de diciembre de 1989. Si bien, en materia de garantías, la norma fundamental a considerar es la Ley de Contratos de las Administraciones Públicas, y en la actualidad, su texto refundido 2/2000, de 16 de junio, puesto que, aparte de ser la norma básica de la materia, en todas las administraciones públicas, es la norma de reenvío, en múltiples casos, dentro de la propia administración local, como veremos seguidamente.

En todo caso, antes de conocer las particularidades que cada regulación concreta nos presenta, vemos conveniente efectuar una formulación general de los aspectos jurídicos y económicos de las principales garantías, dado que como contratos e instrumentos, provenientes principalmente del Derecho mercantil ${ }^{13}$, no han sido suficientemente estudiados, en el campo administrativo y en concreto, en el Régimen Local, por lo que resulta interesante, una visión global de las mismas.

\section{ESTUDIO DE LOS MEDIOS DE GARANTÍA EN LA ACTUALIDAD}

\subsection{Distinción conceptual}

Con DíEz-PICAZO ${ }^{14}$, podemos definir la garantía como «cualquier medio o modo especial de asegurar la efectividad de un crédito». La garantía se puede constituir bien por mandato de una norma legal o reglamentaria, o bien de forma convenida, basada en la autonomía de las partes, o incluso por una decisión judicial, pero, en todo caso, lo fundamental en la misma es que viene a añadir al crédito algo que el acreditado de por sí no tiene, de tal suerte que es esta adición o yuxtaposición la que refuerza al acreedor, con la seguridad de que su derecho será satisfecho.

${ }^{13}$ La remisión expresa al Derecho mercantil, como Derecho supletorio, se establece para el aval, en concreto en el artículo 374 del RCE.

14 L. Dímz-Picazo y A. Gullón, Fundamentos de Derecho Civil Patrimonial, ed. Tecnos, 1986, p. 581. 
En primer lugar, debemos procurar aclarar, por lo menos en lo referente a este trabajo, las distintas y diferentes interpretaciones que del concepto de fianza o garantía se emplean habitualmente, dado que, con cierta frecuencia, tanto la normativa, como por la propia asimilación que de ésta efectúa, la doctrina y la misma administración se confunden y mezclan de forma imprecisa los términos de fianza, garantía, aval, caución, incluso con otras formas de aseguramiento, como medidas cautelares, ajenas totalmente al concepto de garantía.

En principio, en sentido general la fianza, dentro del ámbito propio de las actuaciones administrativas, se puede asimilar a garantía o caución, entendiendo por éstas, con DíEZ- PICAZO, «las que actúan a modo de yuxtaposición que refuerce en el sujeto acreedor la seguridad de que su crédito será satisfecho» y más en concreto la fianza administrativa se asimilaría al tipo de garantía que se determinan en las leyes propias de los contratos públicos, fundamentalmente, como medio de aseguramiento en caso de incumplimiento obligacional, por parte del contratista ${ }^{15}$.

Sin embargo, desde un punto de vista más técnico, debemos entender como fianza, aquella medida jurídica que se identifica con la garantía personal y que se presta, al asumir un tercero el compromiso de suplir la obligación, para cuando no lo haga el deudor principal ${ }^{16}$.

En realidad, entendemos, que los conceptos garantía, fianza y caución están en una relación de género y especie, por cuanto la denominación de garantía que legalmente se establece por exigencia legal sería el encuadre global de las diversas especies, que, dentro de dicho género, podemos encontrar, como son las fianzas, los avales, éstos como subespecie de la anterior y aquellas otras figuras, más novedosas, como el seguro de caución, la prenda por anotaciones en cuenta de valores, y algunas otras que, como iremos viendo, se le asimilan, pero con las que no se deben confundirse, siendo técnicamente el contrato de fianza, la forma tradicional y hasta hace poco más frecuente de prestar garantía personal.

\footnotetext{
15 No en vano todavía hoy, la denominación correspondiente del RCE, aprobado por Decreto 3410/1975, lleva el titulo: «De las fianzas y demás garantías en los Contratos del Estado», si bien, la actual LCAP, denomina el apartado, como «De las Garantías exigidas para los contratos con la Administración».

16 V. Guilarte Zapatero, en Comentarios al Código Civil, Tomo II, AA.VV., 1991.
} 


\subsection{Clasificación}

A la vista de lo comentado, parece interesante hacer una clasificación, no con carácter exhaustivo, de las posibilidades o medios de garantía, que en la actualidad financiera de todos los días nos podemos encontrar. Partiendo para ello, de la formulación efectuada en el campo del Derecho, principalmente en el Derecho mercantil, al presentar éste un mayor número de posibilidades, y que tanto, por su carácter personal, como patrimonial, o por su finalidad, son lentamente traspasadas al Derecho administrativo. Intentaremos, por tanto, recopilar las diversas posibilidades de uso más frecuente, anotando sus principales características, con la finalidad de asegurar su validez y efectividad, e incluso citando fórmulas que sin haber llegado a una asimilación legal, lo pudieran ser en el futuro, como medio de caución o garantía aplicables a los convenios, pactos u obligaciones, que terceras personas deban cumplir ante la Administración Local.

Tradicionalmente por la doctrina se ha venido distinguiendo, de una parte, las garantías que se consideran implícitas, de las convenidas o explícitas. Siendo las primeras las que devienen de normas legales, que proveen de éstas para equilibrar los derechos y obligaciones en las relaciones entre deudores y acreedores. Garantías que en bastantes casos son implícitas, siendo la más representativa de ellas, la responsabilidad universal del deudor a favor del acreedor, contemplada en el artículo 1.911 del Código Civil. Las garantías explícitas, por su parte, serían aquellas que se convienen por las partes como contratos complementarios del principal, que contiene la obligación a garantizar, y es aquí donde se puede establecer una $1 .^{\circ}$ clasificación, según la naturaleza, Personal o Real de las mismas.

\subsection{A. Garantías reales}

Para M. AlBALAdEJO ${ }^{17}$, serían aquellas que aseguran el cumplimiento de una obligación, mediante la concesión de un poder directo e inmediato (Real) sobre una (o varias) cosa ajena, facultando al titular, para si aquélla se incumple, promover la enajenación de ésta y hacerse pago con su precio. La clasificación que de los mismos, habitualmente, se efectúa, sobre dos figuras principales, con diversas variantes según el objeto o la cualidad, de lo puesto en garantía. Así, distinguiremos de una parte, la Hipote-

17 M. Albaladejo, Compendio de Derecho Civil, L. Bosch, 1976, p. 409. 
ca Inmobiliaria, que recae sobre bienes inmuebles, y la Hipoteca Mobiliaria, con una gran variedad, dependiendo del objeto que garantiza la obligación (Vehículos, Barcos, Aeronaves, Maquinaría) y, de otra, la figura también estudiada como garantía Real, que sería la Prenda, que suele recaer sobre cosas muebles, pero también con la posibilidad, en el caso del no desplazamiento del objeto del pignus, sobre bienes inmuebles. Incluyendo dentro de esta figura, de prenda, el depósito en metálico efectuado, ante la Administración, como medio de garantía del cumplimiento de obligaciones.

En todo caso, el análisis a realizar, tanto de las garantías o cauciones reales, como personales, lo será sobre las de un uso más frecuente, bien porque, administrativamente, son recogidas en la legislación con carácter de exclusividad, bien porque, son las de más rápida elaboración o con mayor efectividad ante la misma. Circunstancia ésta, que ha facilitado también el amplio desarrollo comercial a nivel de entidades de crédito y bancarias.

\subsection{B. Garantías personales}

Como ya hemos indicado, serían aquellas que se añaden a la responsabilidad universal del deudor y que tiene carácter personal, al realizarse por otras personas, fiadores, avalistas, y mediante la cual, asumen la obligación accesoria, de garantizar cumplimientos ajenos, en defecto y subsidiariamente de la realización de la obligación principal.

La garantía personal por antonomasia y tradición, es la FIANZA, o mejor dicho el contrato de fianza, según el artículo 1.822 del C. Civil, regulado en el mismo, así como sus modalidades legales, confianza, subfianza o variedades de última generación del mundo mercantil, de tal suerte que podemos encontrar, con Nieto CAROL y MuÑoz Cervera ${ }^{18}$, como particularidades dentro del mismo género o forma de caución, los siguientes medios:

Afianzamiento solidario, pólizas bancarias de cobertura de riesgos, créditos de firma, Avales cambiarios e independientes, Contragarantías, Cartas de patrocinio, intenciones o conformidad, Sociedades de Garantía Recíproca, etc., e incluso variedades últimas, originadas en el campo de la contratación de derivados financieros. Si bien, las más habituales son,

18 U. Nieto Carol y Muñoz Cervera (coordinadores), Tratado de Garantías en la contratación mercantil, Tomo II, Civitas, 1996. 
por su facilidad de gestión, así como efectividad en la ejecución y desarrollo comercial actual, el AVAL BANCARIO y el SEGURO DE CAUCIÓN, si bien la FIANZA SOLIDARIA para deudas de pequeña entidad sigue teniendo su relevancia, que someramente revisaremos en los siguientes apartados.

\subsection{Contrato de fianza}

DíEZ-PICAZO ${ }^{19}$ la define como «obligación accesoria de garantía de una deuda ajena, que asume el fiador y que debe cumplir subsidiariamente en defecto de cumplimiento de la obligación fiada». Técnicamente, debe distinguirse de figuras afines, como el aval independiente, el mandato de crédito, el seguro de crédito, etc. Por el continuo desarrollo de los contratos mercantiles, sobre los estrictamente civiles, es conveniente detenerse con más detalle en la legislación de la fianza mercantil, según el artículo 439 del Código de Comercio, sus características serían:

Sólo se considera afianzamiento mercantil cuando tenga por objeto el cumplimiento de un contrato de esa naturaleza, o cuando intervenga un comerciante o contratista, sujeto al mismo de forma habitual, en el resto de los casos deberá estudiarse, caso por caso, la naturaleza y sujetos, para determinar su régimen jurídico. Los que se presentan ante la Administración, al intervenir normalmente una entidad bancaria, o de seguro, son de carácter mercantil.

El contrato de fianza siempre deberá constar por escrito (art. $440 \mathrm{C}$ de C), dado que sin ese requisito, no tendrá validez ante terceros, siendo, además, ésta una característica genérica de las garantías, ya que se constituyen ad solemnitaten, a partir de la formalización, incluso en las que se perfeccionan por la entrega de cosas. Esta circunstancia, en la teoría de las garantías, la podemos ver de forma más acusada, por ejemplo, en el aval cambiario de la letra de cambio, según se establece en la Ley 19/ 1985, Cambiaria y del Cheque, donde sus artículos 35 y 36 establecen que el mismo se expresará por escrito, indicando a quién se avala, quedando el avalista obligado, en iguales términos que el avalado, incluso cuando la obligación principal fuese nula, salvo por «vicio de forma». En el mismo sentido, el artículo 132, de dicha Ley, para avales como garantías cambiarias, en cheques.

19 Díez-Picazo y A. Gullón, Fundamentos..., obra citada, pp. 581 y ss. 
Por último, jurisprudencialmente en el ámbito del Derecho mercantil, ha existido cierta confusión sobre si la misma es de naturaleza solidaria o rigen, como en la fianza civil, los beneficios de división y excusión. Así, aunque la mayoría de la doctrina es unánime en negar que tenga carácter solidario ${ }^{20}$. De las Sentencias del Tribunal Supremo, de 16 de octubre de 1989 y 7 de marzo de 1992, así parece deducirse. Por esta circunstancia, en las fianzas que deban presentarse ante la Administración, deben siempre hacerse constar, la renuncia a dichos beneficios de excusión o división ${ }^{21}$, según artículo 46 de TRLCAP, no pudiendo darse nunca por incluidos implícitamente, si no son recogidos formalmente.

En cualquier caso, las notas definitorias del contrato de fianza, según vienen reguladas, pueden concretarse de forma resumida en las siguientes:

- Contrato accesorio de otro principal, nota característica de los instrumentos auxiliares de garantía o caución, con la consiguiente relación de subordinación y dependencia de la obligación fiada o principal, sin la que no puede existir, pero manteniendo ambas obligaciones, principal y accesoria, su propia identidad.

- El contrato de fianza es subsidiario, es decir, su realización se pospone al resultado del contrato principal que asegura o cauciona, sin embargo, doctrinalmente, esta nota no ha resultado indiscutida en su significado por la doctrina.

Siguiendo a GUILARTE ZAPATERO ${ }^{22}$, encontramos a este respecto la existencia de tres opiniones doctrinales claras:

- La de aquellos, como AlBALADEJo, que consideran la subsidiariedad como nota natural de la fianza. El fiador, por tanto, es un deudor subsidiario y debe satisfacer su obligación sólo si el deudor principal no cumple, para lo que dispone, entre otros, del beneficio de excusión, debiendo, por ello, el acreedor ejecutar, en primer lugar, al deudor principal. En este sentido, subsidiariedad y beneficio de excusión son una misma cosa.

\footnotetext{
${ }^{20}$ V. Guilarte ZaPATERo, Jurisprudencia sobre fianza y demás garantías, ed. La Ley-Actualidad, 1997, p. 13.

${ }^{21}$ En el mismo sentido, artículo 357 del RCE. Así como la abundante jurisprudencia, que se cita referente a dicho principio, por O. Moreno GiL, Contratos Administrativos, ed. Civitas, 1998, pp. 614 y ss.

${ }^{22}$ V. Gullarte Zapatero, Jurisprudencia..., obra citada, pp. 16 y ss.
} 
- Una segunda opinión niega que la subsidiariedad sea nota característica de la fianza, y ello con independencia de que el fiador disponga o no del beneficio de orden, lo que se explica por el carácter eventual de la obligación del fiador.

- Por último, la doctrina más especializada considera que la subsidiariedad es la esencia en la obligación del fiador y la acompaña inseparablemente, cualesquiera que sea el régimen que sobre el beneficio de excusión sancione el Derecho positivo. La obligación del fiador está en distinto grado y en otro plano, por lo que su exigibilidad presupone siempre la de la obligación principal.

- Otra de las notas definitorias de la fianza, en el Derecho positivo moderno, es que el fiador se puede obligar a lo mismo que el deudor principal, pero nunca a más, por tanto, es inexacto entender que la fianza sólo resulta posible sobre obligaciones susceptibles de sustituir a la del obligado principal, como por ejemplo una suma de dinero, y por tanto que sólo las obligaciones fungibles son aptas para ser objeto de aquélla (una fianza personalísima y tradicionalmente en el origen de éstas, como contrato, es la fianza judicial sustitutoria de pena de privación de libertad). En el ámbito de la administración local, las fianzas siempre se valoran y prestan en términos monetarios.

- La última nota característica de este contrato, que podemos detallar aquí, es que nunca se presume, debiendo constar siempre por escrito o de forma expresa (si es de naturaleza mercantil) y no poder extenderse a más de lo contenido en ella ${ }^{23}$. Por tanto, el criterio básico para fijar el ámbito de la fianza lo marca la función de garantía y el contenido mismo de la obligación fiada. El fiador se obliga in leviorem causam, si bien en la actualidad incluso en el ámbito jurisprudencial, se van admitiendo modificaciones a dichos principios, como es el caso en que se afiance hasta una determinada cantidad, sin fijar exactamente la cuantía de la misma, con lo que la obligación asumida, por tanto, puede ser mayor o menor, pero hasta un límite concreto.

En el campo de las fianzas locales, las notas anteriores, como hemos ido viendo, son totalmente necesarias para la correcta y válida constitución de una fianza, muchas de ellas conforme al articulado del RCE (arts. 370 a 379) han sido expresamente recogidas, como es en el caso del aval.

${ }^{23}$ V. Guilarte Zapatero, Jurisprudencia..., obra citada, pp. 34 y ss. 


\subsection{Aval bancario}

La fianza, en términos del Derecho positivo, aparece como la institución típica de las denominadas garantías personales de la obligación, y si bien no es la única modalidad, opera como una suerte de categoría genérica de las mismas, lo cual no impide, como apunta DíEz-PICAZO ${ }^{24}$, otras construcciones, pero, eso sí, otorgándoles un tinte de excepcionalidad, fundamentalmente porque surgen de la iniciativa o por la autonomía de la voluntad de los interesados, a las que, posteriormente, el Derecho les otorga una regulación concreta. Éste es el caso, por ejemplo, del aval o de ciertos contratos de seguro, como fórmula de garantía.

El aval como garantía independiente tiene un origen incuestionable en las modificaciones, que los particulares van introduciendo sobre la figura de la garantía cambiaria o aval y que, al socaire de las necesidades prácticas de la reglamentación de Contratos del Estado, ha ido adaptándose, de la figura primitiva del aval cambiario a la de garantía de tramitación y «sustantividad independiente», y que se acompaña de una rápida y fehaciente confección, una fácil ejecución y unos menores costes, en caso de tener que realizarse, lo que ha hecho que tenga el aval independiente, un importante desarrollo, como medio o instrumento de garantía, ante la administración pública. Por ello, con RUIz MORENO ${ }^{25}$, podemos definir el mismo como aquella operación, de una entidad bancaria o asimilado, por la que el cliente evita la inmovilización de tesorería, pero asegura o garantiza a un tercero la percepción o pago de las cantidades adeudadas, en virtud de un contrato subyacente.

La regulación concreta de esta figura, conforme al artículo 340 del RCE, viene establecida en los artículos 370 a 379 del mismo, y, en todo caso, deberá sujetarse a las normas del Derecho mercantil. En cuanto a la forma a la que debe adaptarse, los requisitos venían establecidos en el antiguo artículo 376 del RCE, que han sido sustituidos, según establece el artículo 18.5 del RD 390/1996, por los que contiene el modelo, anexo al mismo, como forma obligatoria de constituir válidamente un aval.

Entre las notas comunes de esta figura podemos destacar, de una parte, al intervenir un banco o entidad financiera, tiene siempre naturaleza mercantil, por el sujeto que lo presta, sus notas, por tanto, serían repetición de las de la fianza, ya comentadas, es decir, contrato por el que una entidad

${ }^{24}$ Citado por V. Guilarte Zapatero, Jurisprudencia ..., obra citada, p. 87.

25 J. M. Ruiz Moreno, «La prestación de la fianza en relación al otorgamiento de la tutela cautelar», Rev. de Jurisprudencia. Aranzadi, n. ${ }^{\circ}$ 4713, de 15 de enero de 1999. 
bancaria garantiza en los mismos términos que el contratista o recurrente, ante la Administración, el pago de una cantidad de dinero de forma solidaria, para asegurar las obligaciones que deba de cumplir o una indemnización pecuniaria del deudor en caso de incumplimiento, motivo éste por el que no existe posibilidad de admitir el derecho al beneficio de excusión, regulado en la normativa civil.

Siempre se hará constar que dicho aval se presta solidariamente con el deudor principal. Es decir, debe existir una renuncia expresa y formal del denominado beneficio de excusión, de tal manera que el fiador o avalista asume la obligación principal en los mismos términos, que el deudor, sin posibilidades de admitir excepciones ajenas a la obligación asumida. Como expone acertadamente GUILARTE ZAPATERO ${ }^{26}$, esto no quiere decir, sin embargo, que desaparezca la nota de subsidiariedad de toda fianza, puesto que la entidad crediticia o bancaria paga, responde o cumple, en lugar del deudor, aunque de igual manera, y en el mismo sentido, ni tampoco significa que desaparece la nota de accesoriedad, dado que toda función auxiliar es siempre accesoria de la principal, que garantiza, puesto que no puede existir, sin una obligación válida, por ello, el aval como documento reglamentado formalmente, y con un contenido riguroso, para su válida admisión, requiere que expresamente conste en el mismo dicha diligencia de exclusión.

Otra cuestión que se debe resaltar en la admisión de un aval es la relativa a la entidad avalista, y a la identificación de los firmantes por delegación de la misma, lo que hace preciso siempre el cotejo del apoderamiento concreto. Así, en concreto, se establece en el artículo 377 del RCE, imponiendo la obligación de que en el texto del mismo se haga constar referencia a este requisito y así lo ha venido requiriendo la jurisprudencia, $v r$. gr. la Sentencia del Tribunal Superior de Justicia de Madrid de 9 de mayo de 1994 (Ar. 3599) ha manifestado «la necesidad de que como medio de garantizar las aportaciones que se efectúen por un aval, que se preste por un tercero, el mismo debe estar bastanteado por la Administración, de forma previa». En el mismo sentido por ejemplo, la Sentencia del TS de 23 de marzo de 1988, que establece «que al no constar en documento público y fehaciente la aceptación del fiador de la obligación de fianza, no puede acreditarse que existe la misma», lo que nos demuestra una vez más el carácter extremadamente formalista de este tipo de contrato, tanto en su origen privado, como en su traslado ante las Administraciones públicas.

${ }^{26}$ V. Guilarte Zapatero, Jurisprudencia..., obra citada, pp. 89 y ss. 
Por otra parte, no debemos confundir la necesidad de bastanteo de poderes, con lo que se entiende por legitimación de firmas, que en concreto no es una exigencia legal, sino una posibilidad establecida en el artículo 378 del RCE, pues sólo si se incluyen previamente en los pliegos particulares, se podrá exigir dicha legitimación y así parece que lo ha entendido la Sentencia del Tribunal Superior de Justicia de Madrid, de fecha 14 de mayo de 1998, al establecer: «que la exigencia de que la firma de los apoderados de la entidad que prestan aval, estén legitimadas notarialmente o intervenidas por corredor de comercio, es improcedente al no tener respaldo legal positivo dicha exigencia». Notoria contradicción jurisprudencial, añadimos nosotros, pues, como vemos, siendo requisito necesario el bastanteo, para la correcta formalización, la legitimación de las firmas no lo es menos como garantía de su cumplimiento y ello con independencia de que este recogido con carácter potestativo en el reglamento, si bien, una vez incluido en pliegos, dicha exigencia sería imperativa, en su cumplimiento, por las partes contratantes.

Otros requisitos del documento de aval, según lo establecido en el artículo 18.5 del RD 390/1996, son los que hacen referencia a la constancia en el mismo de la entidad o persona avalada, con identificación plena de ésta, tanto si es persona física como jurídica. Órgano administrativo a cuyo favor o disposición se expide el aval, que debe quedar detallado, y por supuesto concretadas las obligaciones que asume por dicho aval el avalista, así como las garantías que presta, con total precisión del contenido de las mismas, como ya hemos podido ver. La cuantía del aval, siempre valorada en moneda nacional, dado que las obligaciones administrativas de los entes locales son mayormente fungibles y reconducibles a metálico. Admitiéndose, en todo caso, cierta imprecisión en el supuesto de los avales de carácter tributario, dado que, al no poder determinar de forma previa la cuantía de los intereses moratorios en el supuesto de reclamaciones o recursos, sólo con una expresión o dicción aproximada es con la que se debe admitir, si bien, carece, por tanto, de la exactitud numérica.

Constará también el plazo o duración del mismo, habitualmente será superior a la de tramitación del contrato o resolución subyacente, por lo que normalmente se incluyen por tiempo indefinido, o hasta que se autorice expresamente su cancelación, evitando así cualquier limitación a los efectos de las mismas (art. 16 del RD 390/1995). No se conciben avales o fianzas, con mayor vigencia que la de obligación principal ${ }^{27}$.

${ }^{27}$ En este sentido, la Sentencia del TS de 4 de junio de 1990 (Ar. 4839) establece: «Las fianzas que garantizan el resultado de un proceso comprenden, a falta de estipulación expresa, el tiempo durante el que ese se desarrolle y el de ejecución de lo resuelto». 
Una de las notas que más eficacia, como medio de garantía, ha otorgado al aval, es la establecida en el artículo 379 del RCE, donde una vez producido el incumplimiento de la obligación principal, el acreedor queda facultado, por dicho artículo, para dirigirse contra el garante en vía directa, exigiéndole el cumplimiento de la obligación avalada, sin que lo impida ninguna traba de forma previa, como veremos seguidamente.

\subsection{Seguro de caución}

La fórmula por la cual un tipo concreto de seguro puede afectarse como caución o garantía del cumplimiento de obligaciones no es reciente, puesto que sus antecedentes los vemos en la Ley 50/1980, del Contrato de Seguro, de 8 de octubre de 1980, si bien es ciertamente reciente su aceptación como fórmula de garantía de obligaciones a prestar ante la Administración ${ }^{28}$.

Según el artículo 68 de la Ley de Contrato del Seguro, el seguro de caución es «aquel por el cual el asegurador se obliga, en caso de incumplimiento del tomador del seguro, de sus obligaciones legales o contractuales, a indemnizar al asegurado a título de resarcimiento o penalidad de los daños patrimoniales sufridos, dentro de los límites establecidos en la Ley o en el contrato».

Según informe de la Junta Consultiva de Contratación 11/1996, de 7 de marzo, las entidades aseguradoras no pueden prestar servicios de garantía a particulares para presentar ante la Administración, en forma de aval, sino que exclusivamente lo pueden efectuar en forma de seguro de caución (art. 36.1 LCAP).

Consecuentemente, este tipo de seguro se considera como una garantía personal, asumida por la compañía aseguradora emisora de la correspondiente póliza, en la que el tomador del seguro es el obligado en el contrato principal y el beneficiario del seguro, el acreedor de dicho contrato, produciéndose la indemnización, en el caso de que aquel deudor principal incumpla las condiciones establecidas con el acreedor. La compañía de seguros liquidará, entonces, a este último, en forma de indemnización por siniestro y tratará de recuperar el quebranto del deudor principal o tomador del seguro.

\footnotetext{
28 Dicha posibilidad fue introducida por el artículo 36 de la Ley 13/1995, de 18 de mayo, puesto que, con anterioridad, las compañías de seguro emitían las garantías, en forma de avales, en los mismos términos que las entidades bancarias y fue a raíz de este artículo y del informe de la JCC n. ${ }^{\circ} 11 / 96$, cuando se comenzó a emplear la póliza de seguro de caución, con los mismos efectos.
} 
La legislación aplicable a este contrato viene establecida en la Ley del Contrato del Seguro, si bien con la importante salvedad establecida en el artículo 44.2 de la misma, en relación con el 107.2.b) y que establecen, «que no será aplicable a los contratos de seguro por grandes riesgos», entre los que se incluyen los de caución a contratistas, tal y como se determina en la Ley, el mandato establecido en su artículo 2, sobre el carácter imperativo de su contenido. A la vista de lo cual, podemos establecer que, en materia de seguro de caución, como garantía ante la administración, rige en primer término la normativa administrativa, que regula la materia de garantías, LCAP y RD 390/1996 y supletoriamente, a falta de normativa expresa, la establecida en la Ley del Contrato del Seguro. En todo caso y conforme al RD 390/1996, la compañía aseguradora debe contar siempre con legitimidad para operar en el ramo concreto de la caución, y entre los requisitos y efectos necesarios para la admisión de este tipo de garantías, podemos apuntar, entre otros, los siguientes.

El artículo 5 de la citada ley establece que el contrato siempre se formalizará por escrito, siendo obligación del asegurador entregar la póliza correspondiente, para su aceptación, estableciendo el artículo 8 el contenido mínimo de ésta, y conforme al RD 390/1996, los modelos a utilizar son obligatoriamente los establecidos en éste.

Se establece, asimismo, en dicha Ley, una amplia regulación de las excepciones que el asegurador puede oponer al asegurado y que pueden resumirse en: A) De una parte, las que hacen referencia al riesgo, como son la posibilidad de rescindir la póliza, si hay una declaración inexacta de las condiciones del riesgo asegurado (art. 10) y también, si se producen modificaciones de las circunstancias que agraven el mismo, como son no comunicar en el plazo de dos meses al asegurador dicha circunstancia (art. 12.B). Así como aquellas otras obligaciones referentes al pago de la Prima, si por culpa del tomador, no se paga la prima, la ley otorga al asegurado la posibilidad de rescindir el contrato de seguro (art. 15), o cuando no se empleen todos los medios posibles al alcance del asegurado, para aminorar las consecuencias del riesgo (art. 17).

Vista la importancia de estos motivos, se establece por el RD 390/ 1996 y más directamente, en el artículo 47 del TRLCAP, la conveniente aclaración de éstas, así:

- Tendrá la condición de tomador del seguro el contratista y la de asegurado la Administración contratante.

- La falta de pago de la prima, sea única, primera o siguientes, no dará derecho al asegurador a resolver el contrato, ni éste quedará extin- 
guido, ni la cobertura del asegurador suspendida, ni éste liberado de su obligación, caso de que el asegurador deba hacer efectiva la garantía.

- El asegurado no podrá oponer las excepciones que puedan corresponderle contra el tomador del seguro.

Vemos nuevamente una acusada tendencia hacía el formalismo, puesto que al igual que en la figura del aval está presente en toda su confección legal. En cualquier caso, la presentación ante la Administración debe efectuarse en forma de certificado, que debe contener el mismo clausulado que la póliza o contrato suscrito. De tal suerte que, al presentarse ante la Administración, ésta pueda conocer los términos exactos del seguro, debiendo dicho certificado hacer mención expresa «a que la falta de pago del precio o la prima, una vez presentado y expedido el certificado, no habilita al asegurador a excepción alguna», si se le reclama por parte de la administración la caución, o el importe del riesgo asegurado.

En cuanto al régimen de ejecución, a pesar de que muchas de las excepciones citadas, éstas no pueden utilizarse ante la Administración; así, una vez producida la eventualidad, se deberá comunicar a la entidad aseguradora el acaecimiento de la misma. Añadiendo los artículos 18, 19 y 20 de la Ley del Contrato de Seguro que el asegurador o la compañía está obligada a satisfacer la indemnización, al término de las peritaciones necesarias y, en su caso, del importe de los daños, dentro del plazo de 40 días, a partir de la recepción de la declaración del siniestro. La aseguradora está obligada al pago de la prestación, salvo el supuesto de que el siniestro haya sido causado con mala fe, por último, si la aseguradora incurriera en mora, cuando hayan transcurrido tres meses, desde la producción del siniestro y no se hubiera pagado el importe, la indemnización por esta circunstancia se impone judicialmente, pero está preestablecida legalmente y será igual al interés legal del dinero vigente el día del devengo, incrementado en un 50 por 100 y por todo el plazo de demora, hasta el pago completo de la indemnización.

Conforme al artículo 22 de la Ley del Seguro, el plazo máximo de la póliza, no puede ser superior a 10 años, si bien puede prorrogarse, de ahí que el artículo 17 del RD 390/1996 establezca, para cuando el contrato de caución sobrepase dicho plazo, que debe ser de nuevo renovado, durante el último mes de vigencia ${ }^{29}$. En todo caso, dada la temporalidad del contrato de seguro en general, éste deberá establecerse por un plazo superior

29 Artículo 19 del RD 390/1996, de desarrollo parcial de la Ley 13/1995, de Contratos de las Administraciones Públicas. 
al de las obligaciones garantizadas, por lo que como el aval bancario siempre será necesaria la expresión de que se constituye ante la Administración, por tiempo indefinido, o hasta que el asegurado autorice expresamente su devolución. Como ya hemos visto anteriormente para el aval, el seguro de caución debe ser también debidamente bastanteado, con relación a las personas que lo otorgan.

\section{REQUISITOS FORMALES: GARANTÍAS A PRIMERA DEMANDA}

Conforme hemos visto anteriormente al examinar los dos medios de garantía, el aval bancario y la garantía prestada mediante el seguro de caución, éstos han tenido una gran difusión, así como un extraordinario desarrollo en los últimos años. Ello es debido, de una parte, a la penetración comercial y de servicios de las entidades que los facilitan, fundamentalmente bancos y entidades aseguradoras, y, por otra, a su fácil configuración como garantías, dado que al venir extensamente reguladas, en sus aspectos principales, las hace de ágil confección y rápida ejecución.

Esta última cualidad es la razón principal a la que deben su universal aceptación, como medio de garantía, así como la base de su general utilización en las relaciones comerciales o fiscales, y ya no sólo en actuaciones ante las Administraciones, por la facilidad con la que se convierten en metálico, tras el proceso de ejecución de éstas, que las diferencia, por ejemplo, de las garantías sobre bienes, muebles o inmuebles, o del complejo trámite formal a realizar en la ejecución de un contrato de fianza. En todo caso, esta agilidad o facilidad de ejecución es debida a la regulación formal que existe sobre ellas, y principalmente a la inclusión en el texto de dichos documentos de fórmulas o cláusulas denominadas «garantía a primera demanda o a primer requerimiento». Como se establece en el artículo 16.1 (A) y en el 17.3, ambos del RD 390/1996, de 1 de marzo.

El origen y significado de esta cláusula lo encontramos en el Derecho privado, $y$ en el desarrollo que en esta materia ha venido formulado la actividad mercantil. Así, cuando se emplea esta cláusula en las denominadas garantías independientes ${ }^{30}$, se difuminan por dicha circunstancia las notas de toda caución, tanto la de accesoriedad, como la subsidiariedad,

\footnotetext{
${ }^{30}$ Denominadas de esta forma, por documentarse de forma separada a la formalización de la obligación principal, o garantizada, a diferencia por ejemplo, los artículos 36 y 132 de la Ley Cambiaría y del Cheque, que obligan a formular siempre el aval cambiario intrínsecamente unido al modelo de letra de cambio o cheque y por tanto a la obligación principal y a su transmisión.
} 
provocando como consecuencia fundamental de la misma una desconexión entre la deuda del garante y la asegurada, por lo que el avalista, frente a la reclamación del acreedor principal y en contra de lo establecido en el artículo 1.853 del Código Civil, no puede oponer ninguna de las excepciones que le corresponderían al deudor principal. Por ello, hasta cierto punto, parte de la doctrina ha considerado, que en garantías independientes, existe una amplia similitud con la acumulación de deudores, a los que exigirles el pago, ya que en muchas ocasiones, el garante (avalista) aparece más como obligado principal que como subsidiario y deberá asumir, como tal principal, la prestación garantizada, mediando un simple requerimiento del avalado ${ }^{31}$.

La jurisprudencia civil del Tribunal Supremo, $v r . g r$. en la Sentencia de 21 de abril de 1989, ha resuelto que donde la obligación principal esté garantiza con una póliza de seguro de caución a primera demanda, y concretados los riesgos en una cantidad cierta de dinero, «una vez se den los riesgos, y efectuado el primer requerimiento, deberá pagarse, sin excepciones o incumplimientos, debiéndose hacerse frente a la obligación asegurada». La propia jurisprudencia considera dicha cláusula como una garantía atípica, que la autonomía de las partes pueden introducir al contratar un seguro de caución, rechazando la misma, por esta calificación, que el garante pueda oponer cualquiera de las excepciones del contrato subyacente.

Existen, sin embargo, algunas otras Sentencias del Tribunal Supremo, con interpretaciones contrarias a la anterior, sobre la aplicación de la cláusula a primer requerimiento o primera demanda, así, la de 15 de abril 1991 (AZC. 611/1991), donde se establece que dicha claúsula de pago a primera demanda no implica, sin más, la independencia o el desentendimiento de la garantía, respecto de la obligación fiada.

De cualquier manera, la doctrina mayoritaria ${ }^{32}$, y la propia jurisprudencia del TS, consideran que la inclusión de cláusulas a primera demanda o primer requerimiento en el texto de los documentos supone en las denominadas garantías independientes, como avales y seguros de caución, la inclusión de fórmulas convenidas por las partes, por lo que, una vez acaecido el riesgo, el asegurado no puede oponer ninguna de las excepciones que al deudor principal le correspondería conforme al Código Civil, dado que el garante o asegurador actúa aquí más como un deudor acumulativo al principal y, por tanto, «siempre de forma solidaria».

\footnotetext{
31 V. Guilarte Zapatero, Jurisprudencia..., obra citada, pp. 91 y ss.

32 V. Guilarte Zapatero, Jurisprudencia..., obra citada, pp. 92 y ss.
} 


\section{GARANTÍAS REALES}

Son aquellas en las que el cumplimiento de la obligación por parte del deudor es asegurado, para el caso de contingencias o incumplimiento, mediante la entrega presente o futura de un bien real y concreto. La afectación de este bien o cosa de carácter real a la obligación refuerza el derecho del deudor de forma efectiva. Como ya vimos anteriormente, el RCCL admitía la posibilidad de estas garantías en sus diversas fórmulas (Prenda, Hipoteca), y el reciente Reglamento de las Reclamaciones Económico Administrativas, aprobado por el DR 391/1996, de 1 de marzo, las admite como una forma o medio más de garantizar la suspensión de los actos en las reclamaciones de este tipo, ante la Administración Tributaria del Estado.

Entre los diversos tipos de garantía real que podemos encontrar, tenemos los que derivan del régimen jurídico de la Hipoteca, tanto de carácter mobiliario, como inmobiliario, como aquellas otras que provienen, de la figura del pignus o Prenda, sobre cosas concretas, en sus tipos, de con o sin desplazamiento posesorio de la cosa.

ALBALADEJO ${ }^{33}$ entiende como hipoteca «aquel derecho real que recae sobre cosa inmueble, que no pasa a posesión del acreedor y que, como todo derecho real de garantía, asegura el cumplimiento de una obligación, facultando a su titular, si ésta es incumplida a promover la venta del inmueble y cobrarse aquella, sobre su precio»»

Por otro lado, definiremos con L. PUIG FERRIOL ${ }^{34}$ la prenda como aquel «derecho real de garantía que recae, de forma directa e inmediata, sobre un bien mueble, con la finalidad de garantizar un crédito y por ello, en caso de incumplimiento de la obligación asegurada, el acreedor está facultado para instar la enajenación de la cosa dada en prenda, para hacerse pago preferente del crédito, con el precio obtenido por la enajenación.

Existen también otras fórmulas o variedades impropias que presentan ciertos contratos sobre bienes, y que contienen efectos propios de las garantías sobre cosas, como son, de una parte, las condiciones suspensivas y resolutorias, en transacciones sobre inmuebles, o incluso, por otra parte, las consideradas como derecho real de prenda, pero no propiamente sobre cosas, sino sobre derechos y en concreto sobre derechos de crédito o cobro de deudas, como es la denominada prenda de créditos.

33 M. Albaladejo, Compendio de Derecho civil, L. Bosch, 1976, p. 420.

34 L. Puig Ferriol, Enciclopedia Jurídica, Civitas, 1995, p. 5002. 
Brevemente vamos a apuntar las formalidades más importantes que se exigen en las anteriores garantías reales, para su válida constitución, en el régimen local, sin entrar a analizar en profundidad su régimen jurídico, por las limitaciones del presente trabajo y dado que han sido ampliamente tratadas por la doctrina.

\section{HIPOTECA INMOBILIARIA}

Como medio de garantía en el régimen local tiene un uso o utilización poco frecuente, si bien, por ejemplo, el artículo 80 del anterior RCCL lo admitía en determinados supuestos contractuales, también en la legislación de carácter urbanístico es considerada como posibilidad de garantía de aportaciones en procesos de este tipo (cuotas o aportaciones a juntas de compensación, o entes similares) ${ }^{35} \mathrm{o}$ incluso en algún caso puede ser reconocida, para otorgar el aplazamiento de la eficacia de los actos administrativos, al presentar una reclamación o una petición de fraccionamiento, de dichos ingresos públicos, conforme al RREA o al artículo 52 del RD 1684/191990, por el que se aprueba el RGR.

Siguiendo en este apartado a DE LA NuEZ SÁNCHEZ ${ }^{36}$, los requisitos que debería cumplir la Hipoteca Inmobiliaria, para poder ser admitida como garantía, en cumplimiento de obligaciones ante la Administración, principalmente de la Hacienda Estatal, son fundamentalmente los siguientes:

- Deberá cubrir el coste de la deuda impugnada por la reclamación, o el monto de la obligación garantizada, más, en su caso, los intereses suspensivos por tiempo indefinido, en palabras de esta autora, se observa en este aspecto, un posible contrasentido entre ambas circunstancias, así, al establecerse en el artículo 74.7 del RREA la necesidad de que la garantía, lo sea por plazo indefinido, se está reconociendo una indeterminación en cuanto a la cantidad que debe fijarse en garantía, al impedir el cálculo de los intereses de demora, y que se contradice con la necesidad de que en la constitución de la hipoteca inmobiliaria siempre debe determinar el quantum de la obligación garantizada, o cuanto menos, un importe máxi-

\footnotetext{
35 Así, vr. gr., la Ley de 1990, de refundición, «de la legalidad urbanística de Cataluña», establece que: «La garantía para asegurar la obligación de urbanizar puede constituirse en: a) metálico, b) mediante HIPOTECA de los terrenos susceptibles de edificación comprendidos dentro del sector objeto de urbanización... e) mediante Hipoteca en terrenos, dentro del propio término municipal.»

${ }^{36}$ Huesa-Boadilla, De la Nuez Sánchez-Cascado y otros, Las Reclamaciones Económico Administrativas, ed. Aranzadi, 1997, pp. 555 y ss.
} 
mo a cubrir (Hipoteca de máximo), aun en este caso, sin concretarse en una cantidad cierta y exacta.

- La constitución de la hipoteca debe efectuarse siempre en escritura pública e inscripción registral a favor del ente local, dado que son formas ad solemnitatem, y las circunstancias en las que se documentan son constitutivas de su creación. En cualquier caso, conforme al Reglamento de Recaudación, se establece la necesidad de que formalmente, al constituirse dicha garantía, se exprese que la ejecución, en el caso de la hipoteca, se realizará por los órganos de recaudación, mediante procedimiento administrativo de apremio, para evitar equivocaciones sobre posibles aplicaciones del procedimiento establecido en el artículo 131 de Ley Hipotecaria ${ }^{37}$.

Como ya hemos comentado, las rigideces propias del formalismo en materia de garantías nos obligan a detallar en la escritura, tanto la naturaleza del procedimiento, las características del bien entregado en garantía, su localización, descripción del mismo, valoración, justificantes de adquisición, posibles cargas que la misma tuviere, adjuntando todo ello a la propia escritura e incluso certificado de su inscripción en el Registro de la Propiedad, para garantizar siempre su situación registral, ante terceros.

\section{HIPOTECA MOBILIARIA}

Es un derecho real de garantía similar al anterior, pero sobre una cosa mueble, como puede ser un vehículo, o un barco, de forma que el mismo, aun hipotecado, puede cambiar de lugar o ubicación. La hipoteca, por tanto, concede al titular un derecho directo e inmediato sobre la cosa gravada, poder que encierra la posibilidad de disponer de ella, en caso de incumplimiento de la obligación asegurada y con la facultad de cobro preferente sobre el precio del bien hipotecado. Circunstancia que tiene gran importancia y trascendencia para el acreedor de la obligación, dado que, por esta característica, no todos los bienes muebles pueden ser objeto de hipoteca. Existen pocas posibilidades para la válida constitución de esta garantía, según la LHM, puesto que exige, para su efectividad, al poseedor o titular de la prenda una actuación diligente de conservación y uso de la misma ${ }^{38}$. Como forma de garantía, es admitida claramente por el

37 Así, ver el artículo 57.4 del RGR, sobre la ejecución de las garantías, ante la falta de pago, del aplazamiento o fraccionamiento, que remite su realización, al artículo 111 del mismo, sobre ejecución en vía de apremio.

${ }^{38}$ M. Albaladejo, Compendio de Derecho Civil, L. Bosch, 1976, p. 435. 
RREA, donde serán válidas con las mismas formalidades, que las hipotecas inmobiliarias y en el RGR. Su regulación viene establecida en la Ley 16 de diciembre de 1954, de «Hipoteca Mobiliaria», en donde se admite solamente la hipoteca de establecimientos mercantiles, de vehículos a motor, de aeronaves y de maquinaria industrial, y el caso especial sobre la propiedad intelectual e industrial.

\section{PRENDA CON DESPLAZAMIENTO}

Definido como derecho real de garantía que recae de forma directa e inmediata sobre un bien mueble ajeno, con la finalidad de garantizar un crédito a un acreedor principal, y en virtud del cual, en caso de incumplimiento de la obligación asegurada, dicho acreedor esta facultado para instar la enajenación de la cosa y hacerse pago preferentemente, con el precio obtenido por la misma. Supone, por tanto, la entrega en garantía del cumplimiento de obligaciones, de bienes y más ampliamente de cosas, como son las mercaderías o los bienes transportables, buques, aeronaves, etc., e incluso de los derechos susceptibles de apoderamiento ${ }^{39}$, es decir, que sean susceptibles de posesión y además enajenables.

Como en los casos anteriores, es un derecho formal, que se realiza por la entrega de la cosa «en prenda», pero que surte efectos sólo a partir del cumplimiento de las formalidades. Requiere que sea documentada por escrito. Como garantía de cumplimiento de obligaciones por terceros, ante la Administración, tiene un ámbito limitado, por varios motivos. De una parte, sólo es admitida legalmente en las reclamaciones de carácter económico-administrativas, artículo 75 de RREA, así como por el artículo 52.2 RGR. Y, por otra, por los costes que su gestión entraña, con nombramiento de depositario encargado de su conservación, custodia (arts. 136 y ss. del RGR) y posterior realización y ejecución (139 y ss. del mismo), que hacen que su empleo sea cada vez más infrecuente. En cualquier caso, se deberá adjuntar siempre, para su válida constitución, certificado del Registro correspondiente, donde se anote expresamente, las cuestiones referentes a la creación de esta garantía, adjuntando detalle de las características del bien ofrecido, para su identificación, valoración de los mismos, lugar donde se encuentren depositados, y declarando no hallarse afectos a otras garantías ya gravadas, por diferentes motivos. La prenda debe ser documentada siempre en escritura pública, si quiere surtir efectos ante terceros (art. $1.865 \mathrm{CC}$ ).

39 M. Albaladejo, Compendio de Derecho Civil, L. Bosch, 1976, pp. 412 y ss. 


\section{PRENDA SIN DESPLAZAMIENTO}

Podría considerarse, comenta ALBALADEJo, que la única diferencia con la anterior es la de que, en aquélla, el acreedor tiene derecho a poseer la cosa objeto de la garantía y en ésta no, siendo por lo demás igual. Pero no es así, pues la naturaleza de ésta es muy discutida y si bien está recogida en la Ley de 16 de diciembre de 1954, la misma lo hace con amplias limitaciones, pues sólo se aplica a máquinas o muebles identificables, materia almacenadas, aperos o útiles de explotaciones agrícolas, y sobre bienes de valor histórico, artístico o cultural. En la práctica sólo tiene la finalidad de suprimir el inconveniente que supone la privación de un bien productivo, para el deudor que lo entrega en garantía. Se diferencia esta figura de la hipoteca mobiliaria, más que en el tipo de bienes, en la identificabilidad de los mismos y porque, al no haber desplazamiento, la Ley instituye una serie de deberes de conservación para el deudor y de derechos para el acreedor. Estableciéndose para su válida constitución los mismos requisitos, de constancia en documento público y publicidad, en el registro especial, de este tipo de prenda (art. 3 LHM).

\subsection{Prenda de valores por anotaciones en cuenta}

Las posibilidades que, asimismo, presenta la prenda, como figura de garantía y que hemos visto hasta el momento, están siendo ampliadas por las innovaciones que la actividad crediticia y bancaria está realizando en los últimos años. Una de estas novedades se presenta en la posibilidad de entregar valores mobiliarios, como cédulas, obligaciones u otros títulos de origen público o privado, en garantía del cumplimiento de obligaciones convenidas o impuestas. En ese sentido, tras la promulgación de la Ley del Mercado de Valores, se ha producido una importante modificación, al permitirse la opción de pignorar o establecer garantías y gravámenes limitados sobre dichos valores, incluso cuando no se entregan los títulos, sino que dicha entrega se sustituye por las denominadas «anotaciones en cuenta», como forma de constancia o evidencia de las operaciones realizadas con las mismas.

Dicha posibilidad viene recogida expresamente en la Ley 24/1988, del Mercado de Valores, citada expresamente en el artículo 15 del RD 390/ 1996. El artículo 5 de la primera establece que la representación de los valores mobiliarios, bien mediante títulos, bien mediante anotaciones en cuenta, quedarán regulados por las normas de este tipo de mercados. Y en cualquier caso, en los artículos 9 y 10 de la misma, suponiendo su utiliza- 
ción una facilidad más, a la hora de presentar garantías ante la Administración.

Establece el artículo 9 de dicha Ley que la transmisión de los valores representados por anotaciones tendrá lugar por trasferencia contable, donde la inscripción de la misma en dichos registros, a favor del adquirente, producirá los mismos efectos que la tradición o entrega de los títulos. Estableciendo la Ley una presunción de legitimidad del titular inscrito, y por ello con derecho para exigir las prestaciones que el valor representativo otorgue, como son el derecho al cobro de dividendos, usufructos, enajenación, y que sólo pueden enervarse mediante prueba en contrario.

Conforme establece el artículo 10 de la misma la constitución de derechos reales limitativos u otra clase de gravámenes pueden efectuarse sobre los valores anotados en cuenta, dado que la inscripción de los mismos en los registros contables, mediante una ficción jurídica que otorga la ley, equivalen al desplazamiento posesorio de los títulos, citando dicho artículo expresamente la figura de la prenda. Esta circunstancia facilita la constitución de este tipo de garantías, e incluso de otras limitaciones sobre los valores, sin necesidad de que se tenga que producir el desplazamiento posesorio de los títulos, pero con los mismos efectos que su entrega física, y ello tanto, en lo referente a su titularidad, como en lo referente a los actos de gravamen, que sobre los mismos se constituyan.

Por otra parte, para facilitar el giro y tráfico de los valores anotados, establece la ley la posibilidad de que, mediante certificaciones expedidas por entidades encargadas de su registro, y según sus propios asientos contables, se efectúe dicho tráfico de cara a terceros, si bien las certificaciones no confieren, por sí, más derechos que los relativos a la legitimación de quien consta inscrito, como titular, y los gravámenes que soportan.

La Ley establece, asimismo, otras garantías sobre los certificados expedidos a los efectos de evitar la circulación anormal o fraudulenta de éstos. Entre otros podemos citar: sólo se puede efectuar un único certificado, sobre unos valores anotados; las entidades encargadas de los registros contables y los miembros de los mercados de valores no podrán dar curso o transmitir o gravar, ni practicar anotaciones nuevas, mientras no se hayan restituido previamente los certificados expedidos anteriormente. $\mathrm{Si}$ bien, es importante señalar que, conforme al artículo 12 de la misma, los efectos decaen cuando el certificado haya quedado sin valor.

En cuanto a la legislación aplicable a este tipo de garantías, debemos distinguir si son valores públicos anotados, o si son valores privados. El 
artículo 35 de la LCAP, establece ambas posibilidades, si bien el artículo 15 del RD 390/1996, como norma reglamentaria, sólo reconoce aquellos valores de elevada liquidez, en los términos que se disponga por el Ministerio de Economía y Hacienda, considerándose incluidos, entre éstos, los de deuda pública o aquellos otros fondos de inversión, que exclusivamente inviertan en valores monetarios o de Renta Fija.

La inmovilización, como ya hemos visto, se efectuará por la entidad bancaria, y se justificará mediante la expedición de un certificado,según modelo incluido del RD 390/1996 a favor de la Administración, que así será titular de una garantía en prenda o pignorada, y hasta que autorice su cancelación. En este momento, el valor de realización de la misma debe ser del 105 por 100 del importe de la garantía exigida.

Este tipo de garantías, aparte de lo apuntado en el RD 390/1996, se regulan por la Ley 24/1988, del Mercado de Valores, de 28 de julio, para todas las emisiones incluidas en el artículo 2 de la misma, y que pudieran admitirse como valores susceptibles de garantía y las anotaciones de valores de deuda pública, se regulan por el artículo 55 de la misma y su desarrollo reglamentario, en el RD 116/1992, de 15 de febrero.

\subsection{La prenda de créditos}

Como ya hemos comentado anteriormente, la evolución actual del desarrollo y posibilidades de los intermediarios de servicios financieros, Bancos, Gestoras, Aseguradoras, etc., hacen que la innovación y evolución de los medios de garantías sean constantes. Otra posibilidad, como medio de garantía de última generación, proviene también, del Derecho privado y es conocida fundamentalmente en las transacciones de naturaleza bancaria, estando refiriéndonos a la cada vez más citada prenda de créditos, y que podemos definir, con F. PANTALEÓN ${ }^{40}$, «como aquella garantía que se ofrece sobre los créditos o derechos de cobro, que sobre los deudores de un negocio o actividad, se tengan». Los créditos ofrecidos en prenda pueden ser presentes o futuros, y normalmente suelen ser los únicos activos con que cuenta el fiado o contratista, para ofrecer en garantía de la financiación bancaria o, en su caso, de posibles contratos o adjudicaciones. Siendo, por tanto, la cuestión principal a resolver en este apartado, la posibilidad legal y el régimen aplicable, en caso de admisión como medio de garantía, ante la Administración, de la Prenda de Créditos.

40 F. Pantaleón, «Prenda de créditos: Nueva jurisprudencia», Revista La Ley, n. ${ }^{\circ} 4421$, noviembre 1997. 
Como antecedente, manifestar que esta fórmula ya era conocida con anterioridad en la administración local, si bien con cierta variante, ya que el artículo 78 del RCCL establecía:

«Los créditos contra la entidad local interesada se podrán aceptar como garantía, siempre que estén reconocidos y liquidados a favor de quienes la constituyan, como licitadores, adjudicatarios o fiadores de los mismos.»

En dicho reglamento se admitía la posibilidad de considerar los derechos pendientes de cobro como medio de garantía, al ser activos que poseía un tercero, pero limitándolos a los que fueran ante la propia administración contratante, de tal suerte que, por medio de una compensación, realizada por la misma, pudieran liquidarse deudas y créditos recíprocos, en caso de ejecución de garantías.

De otra parte, el artículo 368 del RCE establece que:

«El gobierno podrá acordar para los contratos de obras, con determinadas circunstancias, la constitución de garantías especiales, mediante retenciones de certificaciones de obra, en una cuantía proporcional al importe de las mismas y que no podrá exceder, en ningún caso, del 10 por $100 . »$

Garantía ésta, que también viene recogida en el artículo 41.3 del TRLCAP, y supone un medio especial de asegurarse el cumplimiento de ciertos contratos, por parte de la Administración, mediante la retención o descuento en los pagos del precio, pero que, a pesar de las similitudes apuntadas, no se deben de confundir ambas, por las particularidades existentes, en la construcción del derecho real de prenda.

En la actualidad, la posibilidad de garantizar obligaciones con derechos, no esta expresamente tipificadas en el régimen local, pero, como acertadamente ha comentado J. GARCÍA DE ENTERRÍA ${ }^{41}$, la expresión contenida en el artículo 100 del TRLCAP, al establecer que: «Los contratistas que conforme a los artículos anteriores, tengan derechos de cobro frente a la administración, podrán ceder el mismo conforme a derecho». Ha supuesto una novedad con relación al régimen anterior, para quien la cesión de créditos y la ausencia de toda referencia expresa en la misma a las certificaciones de obra ha supuesto un claro propósito de reconducir la transmisión de los derechos de cobro, hacia la figura común y tradicional de la «cesión de créditos» y de difuminar, por ello, los aspectos carturales y documentales de la misma.

${ }^{41}$ Citado por Ballesteros Fernández y otros, Contratos..., obra citada, pp. 565 y ss. 
Si esto fuera así, vemos que se abren claras posibilidades, con dicho artículo, ya no tanto para la figura, con gran tradición jurídica ante la Administración, como es del endoso de certificaciones o cesión total de un crédito, sino también para la prenda, entendida ésta como cesión limitada, al entregarse exclusivamente el crédito con fines de garantía, sobre el cumplimiento de actos futuros.

Si además, como apreciamos con A. Quirós RoldÁN ${ }^{42}$, el artículo 145 del todavía vigente RCE facilita dicha posibilidad, pues establece que «las certificaciones que se expedirán precisamente a nombre del contratista, serán transmisibles y pignorables conforme a derecho». Podemos concluir con que el ordenamiento administrativo contractual actual admite la figura de la prenda de créditos, como forma de garantía, siempre que recaigan sobre cosas muebles susceptibles de posesión y que sean enajenables, entendiendo por cosas, tanto bienes, como derechos ${ }^{43}$.

Vemos que, legal y jurisprudencialmente, la prenda de derechos, como medio de garantía, va penetrando no sin dificultad entre el resto de medios. De ahí que, en su estudio, consideraremos la misma sólo en los aspectos de su exigencia formal, dadas las limitaciones del presente trabajo, examinando cuáles son los requisitos y formalidades estrictas que han de cumplir, para su plena validez, como medio de garantía. Y entre ellos, primeramente, los correspondientes al de traspaso posesorio, como forma de constitución de la prenda y, en segundo lugar, la notificación al deudor, incluso la forma sustitutoria de ésta, mediante la toma de razón contable ${ }^{44}$.

En cuanto al primer aspecto, del traspaso posesorio, la jurisprudencia tiene establecido, en lo referente a la constitución, Sentencia TS de 17/7/1990 (RJA 10566):

«En principio el régimen jurídico de la constitución y ejecución de la prenda es distinto, según que ésta recaiga sobre un derecho poseíble o tenga por objeto uno que no tenga tal carácter. En el primer caso, será imprescindible la tradición adecuada, para poner al acreedor prendario, en posesión del derecho. En el segundo, se habrá de acudir a algún procedimiento que produzca los mismos efectos, de la transmisión posesoria, principalmente la indisponibilidad del derecho gravado, por parte de su titular. La doctrina se ocupa de este problema al tratar de la prenda de créditos, por ser éstos los derechos no poseíbles, más frecuentes.»

\footnotetext{
42 A. Quirós Roldán y otros, Las certificaciones de obra, ed. El Consultor, 1998, pp. 254 y ss.

43 En este sentido, ver M. Albaladejo, Compendio de Derecho Civil, L. Bosch, 1976, p. 416.

44 A. Quirós Roldán y otros, Las certificaciones de obra, ed. El Consultor, 1998, pp. 255 y ss.
} 
Para los tratadistas del Derecho común, que han estudiado con mayor profundidad la figura, la prenda de créditos presenta, en cuanto a su naturaleza y forma de constitución, dos interpretaciones irreconciliables:

- De una parte, la de aquellos que la consideran una prenda de cosas, conforme a la regulación establecida en el Código Civil para el derecho real de prenda, lo que requiere, por tanto, su documentación en instrumento público y notificación fehaciente al deudor del contrato. Único supuesto que tendría, según este planteamiento, efectos constitutivos. Para F. PANTALEÓN ${ }^{45}$, esta circunstancia es sumamente formalista y contraria a la celeridad que, como instrumento de garantía, la misma siempre requiere.

- De otra, y siguiendo a este autor, en su clasificación, estarían los que la asimilan a una prenda de derechos, por lo que, la misma, no estaría reconocida en el Derecho español, dado que los codificadores españoles intencionadamente no la admitieron. Motivo que dejaría únicamente abierta la puerta a su configuración, como contrato atípico, al amparo de la autonomía de las partes. Admitiéndose dicha posibilidad, nuestro ordenamiento lo permitiría, pero incluyéndose, en documento privado y con la previa notificación al deudor, si bien la misma no sería requisito constituyente, por lo que, con esta forma, el acreedor pignoraticio carecería de privilegio alguno frente a los demás acreedores del deudor.

En cualquier caso, siguiendo a QUIRÓs ROLDÁN ${ }^{46}$, ante la Administración vemos que es necesaria, lo mismo que para el endoso de certificaciones, la toma de razón contable o conocimiento fehaciente de ésta, si ésta quiere surtir los efectos propios, y ello porque así lo establecen, tanto el artículo 100 de la LCAP, como el 145 del RCE, y porque es imprescindible para evitar cesiones simultáneas de un mismo crédito, si éste puede ser notificado, sin el conocimiento previo de la administración, haciendo por ello «imprescindible» la diligencia «única» de toma de razón o constitución, y siendo necesario que se formalice en documento público, conforme al artículo 1.865 del Código Civil, para que pueda tener efectos, ante terceros, ya que «no surtirá efecto la prenda contra tercero, si no consta en instrumento público la certeza de su fecha».

Como ya hemos comentado, en la actualidad, en el ámbito administrativo, las posibilidades de este tipo de garantía son limitadas, si bien no de-

45 F. Pantaleón, «Prenda de créditos: Nueva jurisprudencia», Revista La Ley, n. ${ }^{\circ} 4421$, noviembre 1997.

46 A. Quirós RoldÁn y otros, Las certificaciones de obra, ed. El Consultor, 1998, pp. 255 y ss. 
ben rechazarse totalmente. En su caso, deberá siempre documentarse formalmente, si lo que se pretende, como comenta CRUZ MORENO ${ }^{47}$ es colocar al acreedor pignoraticio, en el caso de la prenda de crédito, en una posición similar a la que ostenta, en el caso de la prenda de cosas corporales. Deben, pues, detallarse los créditos o derechos que se ofrecen en garantía, con una identificación completa en su valoración.

Las limitaciones principales que encontramos a la admisión de la misma se ponen de manifiesto en el trámite de su ejecución, dado que, según el Derecho privado, para su realización se establecen dos procedimientos; o bien se requiere subasta notarial, o en el caso de valores cotizables, según el Código de Comercio, su venta deberá realizarse en los mercados correspondiente. La jurisprudencia, sin embargo, ha entendido, sentencia citada, de 17 de julio de 1990: «En general podrá utilizarse cualquier procedimiento, siempre que, a través de él, se consiga un precio adecuado mediante realización de la cosa empeñada». Circunstancia ésta, que como facultad realizable, lo es a criterio exclusivo del acreedor, que podrá utilizar dichos medios de realización o cualesquiera otros, que considere oportunos.

Llegados a este punto, y tras este repaso de las diversas formas o medios conocidos y más habituales de prestar garantía ante la Administración pública, debemos considerar el régimen jurídico positivo, a los efectos de conocer las posibles limitaciones de algunos de estos medios, en su aplicación concreta. Así, segregaremos, dentro del conjunto de legislación local, aquellos tres apartados, referentes a sectores competenciales concretos y que con mayor frecuencia utilizan de los instrumentos de garantía, en su tramitación y que son los referentes a:

- Contratos administrativos y procedimientos de contratación sometidos a la Ley de Contratos de Administraciones Públicas (RD-L 2/2000). Procedimiento éste de gran importancia aplicable directamente a los entes locales, artículo 1.2 de dicha Ley, y que, como ya hemos visto, tiene, además, carácter supletorio en el Régimen Local, ante una falta de regulación expresa en otros campos, $v r$. gr. en la de gestión de servicios o bienes locales ${ }^{48}$.

${ }^{47}$ M. Cruz Moreno, «La prenda de créditos», Rev. de Derecho Inmobiliario, n. ${ }^{\circ}$ 613, citado por A. Quirós Roldán, op. cit.

48 Sobre la jerarquía de normas concretas aplicables, en materia de contratos en la Administración Local, se puede ver J. L. Rivero YSERn, Manual de Derecho Local, ed. Civitas, 1999, pp. 307 y ss. 
- Medios de garantía en materia de Hacienda Local, tanto en lo referente a suspensión de actos de naturaleza tributaria o de ingreso de Derecho público, cuando se solicita, en la interposición de recursos o reclamaciones, como la referente a cuestiones de aplazamientos y fraccionamientos de pagos de exacciones o ingresos, conforme al Reglamento de Recaudación (RGR).

- Asimismo, la utilización de nuevas modalidades de resolución administrativa de forma convenida (art. 88 LPAC), y que en materia urbanística, ha tenido un amplio desarrollo, hace necesario que someramente nos detengamos en los medios que aseguran el cumplimiento de dichos convenios y demás actuaciones urbanísticas ${ }^{49}$.

Efectuaremos, por último, algunas reflexiones sobre las necesidades de garantías en otros campos de la vigente regulación del Régimen Local, postulando ciertas conclusiones, sobre el análisis realizado.

\section{ESTUDIO DE LAS GARANTÍAS NECESARIAS EN LA LEY DE CONTRATOS DE LAS ADMINISTRACIONES PÚBLICAS}

Como comenta BALLESTEROS FeRnÁNDEZ ${ }^{50}$, «tradicionalmente se ha venido exigiendo a quienes concurren a los procedimientos de selección del contratista, que éste preste garantía de la seriedad de las ofertas y que, adjudicado el contrato, el empresario adjudicatario preste garantía de la correcta ejecución del mismo».

La Ley de Contratos Administraciones Públicas (LCAP), tras las diversas modificaciones, por las Leyes de Presupuestos del Estado, así como por la refundición de su texto, mediante el Real Decreto Legislativo $2 / 2000$, de 16 de junio, sigue siendo el régimen legal aplicable a los entes locales en la realización de sus contratos (art. 1 de la misma).

En la misma se continúan exigiendo los distintos tipos de garantías conocidos tradicionalmente, tanto las de carácter provisional, a todo interesado en el procedimiento de concurso o subasta, abierto o restringido, etcétera, pero ahora, de forma obligatoria, sólo a las que superen una can-

\footnotetext{
49 Sobre la valoración, utilización y efectos de los convenios urbanísticos, por todos, vide Ramón PARADA, Derecho Administrativo, vol. III, Ed. Marcial Pons, 1998, pp. 350 y ss.

50 A. Ballesteros Fernández y otros, Contratos de las Administraciones públicas, ed. El Consultor, 1997, p. 381.
} 
tidad determinada, como las definitivas, una vez adjudicados los contratos regulados en dicha Ley. La naturaleza y finalidad de ambas es distinta, de una parte, la fianza provisional para la doctrina y la jurisprudencia responde a una especie de arras penitenciales o de aseguramiento (STS $4 / 7 / 84)$, si bien otros autores ${ }^{51}$ no lo consideran así, puesto que manifiestan, que junto con la incautación de la fianza provisional en caso necesario, el contratista responde de los daños y perjuicios mediante una indemnización separada, por lo que la fianza respondería más en concreto a este tipo de idea indemnizatoria, que, con carácter de mínimo, se calcula de forma objetiva y previa. Mientras que las garantías definitivas responden a la idea de pena o sanción, por incumplimiento culpable del contratista. Circunstancia, sin embargo, que no culmina en sí misma, las posibilidades indemnizatorias, dado que pueden abrir paso, una vez agotada ésta, a un resarcimiento complementario a dicha fianza.

El TRLCAP, en su artículo 36, establece otros tipos de garantías, como son las denominadas garantías globales, para su empleo como alternativa a lo establecido con carácter general por los contratistas habituales ante las administraciones, y que deban presentar varias con referencia a los distintos contratos que celebren con la misma, sin una especificación singular para cada uno. Esta garantía responde de forma genérica y permanente de un contrato, y en los mismos porcentajes que la provisional o definitiva. Las garantías especiales como son las que tienen un carácter adicional, de hasta el 6 por 100, por exigirlo así el órgano de contratación, que podrá ser, incluso de hasta un 10 por 100 del importe de adjudicación, si bien no acumulativa a la garantía definitiva.

En el supuesto recogido en el artículo 36.4 de la Ley se establece: «En casos de adjudicación a un empresario cuya oferta hubiera estado incursa en presunción de temeridad, podrá exigirse a dicho empresario una garantía definitiva del 20 por 100 del importe de la adjudicación». Este artículo fue modificado, por la Ley 53/1999, que exigía una garantía igual al importe del contrato incurso en temeridad. Y que se anticipa a la garantía complementaria establecida en el apartado siguiente de dicho artículo 36, donde con carácter complementario, se podrá establecer una garantía de hasta el 16 por 100 del precio del contrato, si así lo establecen los pliegos, y a la vista de la baja presentada por la oferta seleccionada, en relación a la media de las ofertas del procedimiento y que deba considerarse como anormalmente baja.

51 E. García-Trevijano GarnicA, «Las Garantías en los contratos administrativos», en Comentarios a la Ley de Contratos de las Administraciones Públicas, ed. Civitas, 1996, p. 231. 
Debemos, dentro de este apartado, hacer una breve referencia a las excepciones que vienen establecidas en la LCAP, pues si bien el artículo 40 de la Ley dice:

«Sin perjuicio de lo establecido, anteriormente, sólo quedan excluidos del requisito de constitución de garantía, las entidades que tengan reconocida esta excepción, por las leyes...»

Existen dentro de su articulado variadas excepciones a este principio de Universalidad. Así, los órganos de contratación podrán eximir de fianza provisional, a los contratos de cuantía inferior, a la señalada en artículos 135.1, 177.2 y 203.2 de la misma. En los contratos privados de la Administración, será facultativa para el órgano de contratación, la exigencia de la garantía definitiva. Lo mismo ocurre con los contratos de consultoría y asistencia técnica, pues el artículo 37 establece que si se hace constar en los pliegos de condiciones, podrá eximirse de garantía, en dichos contratos. Incluso por autorización del Consejo de Ministros, dice el artículo 38.2, en el caso de la Administración Local, entendemos que el pleno municipal ${ }^{52}$, en los contratos de gestión de servicios, puede eximirse de las correspondientes garantías. La última excepción es la establecida en el artículo 39 de la Ley, para contratos de suministros, referentes a entregas de bienes de forma sucesiva, sin determinar cantidad previa, suministro de bienes que sean de fácil deterioro y en los de «Leasing y Renting» y, por último, cuando sea suministrado por empresa extranjera, de acuerdo a las prácticas del comercio internacional.

El artículo 35 del TRLCAP establece, como únicos medios de prestar garantía o caución, en un procedimiento contractual, los que se detallan a continuación, por lo que entendemos, de la redacción legal del texto, que son un número cerrado, sin posibilidad de admisión de otras, y ello, porque la Ley impone en dicho artículo un imperativo «Habrá de ser constituida», y en el artículo 36, para las garantías definitivas, un rotundo «habrá de constituirse», por lo que no hay posibilidad a la admisión de otras figuras, de las que ya hemos estudiado algunas. Los medios de prestar las mismas, son por tanto, conforme a estos artículos 35 y 36 de la Ley, las siguientes:

1. ${ }^{\circ} \quad$ Mediante depósito en metálico o en valores públicos o privados. Según modificación introducida en la LCAP por la Ley 13/1999, estos últimos, con las limitaciones, ya vistas que se entregarán en la Caja General de Depósitos, o a disposición de las demás Cajas Territoriales, bien de la

52 F. Sosa Wagner, La gestión de los Servicios públicos Locales, ed. Civitas (4. ${ }^{a}$ ed.), 1999, p. 128. 
entidad local o de la correspondiente Comunidad Autónoma. Como acertadamente comenta GARCÍA-TREVIJANO ${ }^{53}$, éste es un caso de entrega de valores en prenda o pignus bien mediante entrega física, bien por anotaciones en cuenta, por lo que dado que su principal finalidad es la de garantizar una obligación de la que trae su causa, los intereses y rentas que los mismos generan, corresponden al propietario y no al poseedor pignoraticio. De ahí, el requisito de la intervención de corredor colegiado, para la válida realización, cuando se efectúan a través de una institución financiera.

2. ${ }^{\circ}$ Mediante Aval prestado por Banco, Caja de Ahorros o Cooperativa de Crédito, Establecimiento Financiero (esta posibilidad introducida por Ley 13/1999), o Sociedades de Garantía Recíproca, del que ya hemos comentado anteriormente las características del mismo y su regulación.

3..$^{\circ} \quad$ Por último, mediante la figura del contrato de seguro de caución, por entidad aseguradora, autorizada para actuar en dicho ramo, pudiendo en este caso expedir certificado de seguro, que se presentará ante el órgano de contratación.

En comparación con la anterior redacción de la Ley de Contratos del Estado, vemos que se presentan algunas diferencias, fundamentalmente en el primer apartado, así, se admiten los valores de carácter privado, a los efectos de depósito en prenda, en las Cajas correspondientes, sin necesidad de que estén tutelados o avalados por el Estado o cualquier otro ente público, si bien consideramos que, para cumplir tal finalidad como garantías, tienen que tener una capacidad de liquidez máxima, dado que, a nivel reglamentario, se sigue manteniendo dicha exigencia, para su válida admisión, en el artículo 15 del RD 390/1996.

Este artículo limita, para cuando se desplacen los títulos, que su entrega será en la Caja General de Depósitos o establecimientos similares, que los mismos serán representativos de deuda pública, Letras del Tesoro, Bonos u otros valores de Renta Fija. Por lo que, si son nominativos, la circunstancia de cesión se deberá escriturar en documento, a disposición de la Administración contratante y en el caso de títulos al portador, la entrega, con carta de pago, resultará suficiente.

Si no existe desplazamiento de títulos, conforme a la Ley 24/1988, del Mercado de Valores, y la garantía se ofrece mediante «anotaciones en

53 E. García-Trevijano Garnica, El Régimen de las Garantías en la contratación administrativa, ed. Civitas, 1997, pp. 60. 
cuenta», se entregará certificado de inmovilización registral sustitutorio. Y que supone una constitución de derechos reales limitativos y otras gravámenes sobre valores representativos, por medio de anotaciones en cuenta, que se realizan a instancia del titular y que deberán inscribirse en los registros correspondientes. Asimismo, el artículo 12 de dicha Ley establece que podrán acreditarse mediante certificaciones, que sean oportunamente expedidas por las entidades encargadas de los registros contables, de conformidad con los asientos correspondientes. Las entidades, no podrán dar curso a las trasmisiones o gravámenes, ni practicar las correspondientes inscripciones, si el disponente no ha restituido las certificaciones expedidas anteriormente a su favor.

Conforme al artículo 15 del Real Decreto 390/1996, de desarrollo parcial de la Ley de Contratos, cuando los valores sean privados, deberán tener un valor nominal superior a la garantía exigida y tener una valor de realización de al menos el 105 por 100 de la misma ${ }^{54}$. Según los anexos que acompañan al RD 309/1996, en donde se establecen los modelos obligatorios para la formalización de las garantías admisibles, cuando se pignoren valores por anotaciones en cuenta, o mediante participación en fondos de inversión, será requisito necesario la intervención de corredor colegiado de comercio.

\section{PARTICULARIDADES EN LA LEY DE HACIENDAS LOCALES}

Dentro de los procedimientos determinados por la Ley Reguladora de las Haciendas Locales (LHL), principalmente en dos de ellos, se requiere por mandato legal la prestación de garantías o cauciones que aseguren el buen fin del mismo. De una parte, los necesarios para la suspensión del procedimiento de cobro de un ingreso tributario o de Derecho público, cuando así se solicita, al presentar una reclamación o recurso impugnando una liquidación tributaria, por ejemplo, mediante el recurso de reposición del artículo 14.2 de la LHL. La finalidad de este tipo de garantías la encontramos en asegurarse el privilegio de la ejecutoriedad de los actos con que cuentan las Administraciones y en concreto la presunción de le-

\footnotetext{
${ }^{54}$ En relación a lo comentado, la reciente Sentencia del Tribunal Superior de Galicia (Sala de lo Contencioso de 22 de febrero de 1999. La Ley 7623/1999), no ha admitido como garantía, la presentada en acciones de una empresa, según valoración realizada de acuerdo al balance, por no cubrir el valor de realización o ejecución de las mismas el importe exigido, debido a la movilidad que presentan dichas acciones, y que resulta cambiante, de acuerdo con sus balances anuales.
} 
gitimidad de los mismos, y que en materia tributaria se establece en el artículo 8 de la Ley General Tributaria.

De igual manera, otro procedimiento que requiere la presentación de garantías o cauciones es aquel en el que, a instancia de parte, se realiza por la administración de la Hacienda Local un aplazamiento o fraccionamiento del importe del pago del tributo o cualesquiera otro de ingreso de Derecho público, conforme al Reglamento General de Recaudación (RGR), difiriendo el cobro de la deuda, en unos plazos por encima de los reglamentarios de pago. Su naturaleza, por tanto, sería idéntica a la anterior, pues intentaría asegurar la efectividad del pago de la deuda, ante una demora autorizada, al sujeto pasivo en el cumplimiento de su obligación.

El estudio de las garantías que, dentro de la Hacienda Local, requieren estos procedimientos, lo efectuaremos analizando, en cada tipo de ellos, qué garantías son las admitidas y con qué carácter, para, una vez determinado esto, examinar exclusivamente, los aspectos formales, para su válida constitución.

En relación con la suspensión que se insta a la administración local, cuando se presenta ante la misma un recurso de reposición de acuerdo con la LHL, tras la modificación que se ha producido, en el artículo 14 de la misma, por la Ley 50/1998, que ha venido a completar el régimen jurídico de éste, vemos en dicha Ley, en lo concerniente a las garantías exigidas, que éstas se han ampliado, sobre las incluidas anteriormente en dicho artículo 14 LHL, y que decía:

«Para interponer el recurso de reposición, contra los actos sobre aplicación y efectividad de los tributos locales, no se requerirá el previo pago; no obstante la interposición del recurso, no detendrá la acción para el cobro, a menos que el interesado solicite la suspensión de la ejecución, a cuyo efecto, será indispensable acompañar garantía suficiente, que cubra el total de la deuda tributaría. A tal efecto no se admitirán otras garantías que las siguientes:

a) Depósito de dinero efectivo o valores públicos, en la caja general de depósitos, o en la de la entidad interesada.

b) Aval o fianza solidaria prestado por Banco, Banquero registrado, Caja de Ahorros o Cooperativa de créditos.

c) Fianza personal y solidaria de dos contribuyentes de solvencia, para deudas de menos de 100.000 ptas.

En la actualidad, dicho artículo 14.2 establece en su letra I) «Que no obstante, en los mismos términos que para el Estado, podrá suspenderse la ejecución del acto impugnado mientras dure la sustanciación del recur- 
so aplicando lo establecido en el RD 2244/1979 y en el RD 391/1996, de 7 de septiembre, por el que se aprueba, el Reglamento de la Reclamaciones Económico-Administrativas». Ampliando, por tanto, las posibilidades o medios para presentar garantías, al remitir en bloque a la legislación del Estado en esta materia. Redacción muy criticada por parte de la doctrina más cualificada, por todos, ARAGONÉs BELTRÁN ${ }^{55}$, en lo que supone una deslegalización de la materia de garantías, al dejarse exclusivamente a la vía reglamentaria su concreción y delimitación.

La modificación establecida, tras la publicación del RD 391/1996, de 1 de marzo, por el que se aprueba el Reglamento de las Reclamaciones Económico-Administrativas, en este apartado ha supuesto la ampliación de las posibilidades y medios de prestar garantía y caución, dado que, en las reclamaciones presentadas ante los TEA, bien por modulación de la jurisprudencia, bien por innovaciones doctrinales, han sido pioneras, en extender las posibilidades, incluso en ciertos casos sin necesidad de garantía, cuando se demuestre que puede existir perjuicio grave, o que se ha incurrido en un error material o de hecho, que deba ser rectificado. Si bien la antigua redacción del artículo 14 de la LHL ya contemplaba esta posibilidad, pues textualmente contenía:

«En casos muy cualificados y excepcionales, podrán, sin embargo, las entidades acreedoras acordar discrecionalmente, a instancia de parte, la suspensión del procedimiento sin prestación de garantía alguna, cuando el recurrente alegue y justifique en su solicitud la imposibilidad de prestarla o demuestre fehacientemente la existencia de errores materiales o aritméticos en los actos sobre aplicación y efectividad de los tributos locales».

Como acertadamente sintetiza CHECA GONZÁLEZ ${ }^{56}$, la aplicación al recurso de reposición local, de lo establecido en el RREA, presenta en cuanto a las formas de la suspensión tres tipos: de una parte, la denominada suspensión AUTOMÁTICA del procedimiento, presentando las garantías que podemos llamar clásicas o tradicionales, y que eran las establecidas como únicas en la anterior redacción de la Ley, es decir, para conseguir la suspensión de carácter automático se deberán presentar únicamente las garantías que se detallan en el artículo 75.6 del RD 391/1996:

- Depósito en metálico o en valores públicos, entregados (Prenda) en la Caja General de Depósitos o establecimientos similares de otras Admi-

\footnotetext{
55 E. Aragonés Beltrán, Anuario de Hacienda Local, ed. Marcial Pons, 1999.

56 C. Checa González, La revisión de los actos tributarios locales, ed. EDERSA, 1999, pp. 135 y ss.
} 
nistraciones. Si es «Deuda Pública» anotada, se aportará certificado de inmovilización ${ }^{57}$. Recíproca.

- Avales o fianza solidaria por Banco, Cajas de Ahorro y Sociedad G.

- Fianza personal y solidaria de dos contribuyentes de solvencia del término, pero sólo para deudas menores de 250.000 ptas., la fianza en este caso es solidaria, puesto que, junto con el patrimonio propio, se garantiza la deuda con el ajeno que se ofrece en caución, dado que sólo así se garantiza plenamente la obligación.

DE LA NUEZ-SÁNCHEZ-CASCADO ${ }^{58}$ ha comentado, para el ámbito estatal, si realmente este tipo de suspensión es o no un acto administrativo, por el carácter automático de la misma, al no determinar dicho reglamento la necesidad de resolución y notificación de la suspensión al particular, y dado que no se puede argumentar que sea requisito necesario, para su validez, que deba ser expresamente acordada. En el ámbito local, corresponde al órgano que dictó el acto (art. 14.I LHL).

En cuanto al otro tipo de suspensión, de carácter NO AUTOMÁTICA, según el artículo 76 del RREA, las garantías que se exigen lo serán a criterio del Tribunal, por lo que no vemos impedimento de que sean excepcionalmente admitidas por el órgano correspondiente de la administración local, siempre que se consideren como suficientes, económica y jurídicamente. En principio, cualquier garantía puede ser admitida como válida, fundamentalmente, las ya comentadas en la parte general de este trabajo, como son hipotecas, prendas de bienes muebles, semovientes, valores, etc. En el caso de la administración local, las mismas, si bien jurídicamente deben admitirse las de tipo real, tienen escasa virtualidad práctica, circunstancia que hemos analizado en anteriores trabajos ${ }^{59}$, por lo complejo de su tramitación y lo perentorio del plazo del recurso. En cualquier caso, deben cumplir siempre los requisitos formales, al no considerarlo un acto discrecional, sino reglado, puesto que así lo establece el artículo 76.12 del RREA: «la resolución deberá denegar la suspensión, cuando no concurran los requisitos legales, o no resulte acreditado, o

\footnotetext{
${ }^{57}$ Hacemos notar en este punto, la no admisión de la posibilidad de prenda sobre valores privados.

${ }^{58}$ Huesa-Boadilla, De la Nuez Sánchez-Cascado y otros, Las reclamaciones económico-administrativas, ed. Aranzadi, 1997, pp. 555 y ss.

59 J. P. ViÑAs Bosquet, «Breve análisis del recurso de Reposición en la LRHL», Rev. Hacienda Local, n. ${ }^{\circ} 85,1999$.
} 
cuando siendo necesarias las garantías ofrecidas, resulten insuficientes para asegurar la efectividad del acto de suspensión», y a mayor abundamiento, dado que la garantía, conforme al artículo 14.1.c) de la LHL, debe tener validez, en su caso, en las instancias judiciales, deberá, por tanto, cumplir los requisitos que la legislación de dicha jurisdicción establezca como necesarios.

El otro procedimiento en el que se obliga al contribuyente a prestar garantía es el correspondiente al aplazamiento y fraccionamiento del pago, regulado en el artículo 48 y siguientes del RGR, en la administración local que requieren garantías para su ejecución, en los mismos casos que se establecen en dicho reglamento. En este sentido, el artículo 52 del mismo establece que el aval bancario solidario será la fórmula principal para solicitar el aplazamiento. Si bien, cuando no fuere posible el mismo y así se justifique, o cuando con ello se comprometa seriamente la viabilidad de una empresa, se podrán admitir algunas de las siguientes:

Hipoteca Inmobiliaria, Mobiliaria, Prenda, con o sin desplazamiento, Fianza personal y solidaria y cualesquiera otras, que se consideren suficientes. Por lo que acertadamente, J. I. Moreno FERNÁNDEZ ${ }^{60}$, entre otras, ha enumerado las siguientes:

La presentación de nóminas, sueldos o pensiones.

Los seguros de vida, rentas temporales o vitalicias.

Los frutos o rentas de toda especie.

Las opciones contractuales.

Las mercaderías o existencias de un negocio.

Los derechos de cualquier clase, como, por ejemplo, de traspaso, de crédito, etc.

Comprobamos también, en este apartado del RGR, que no existe un número cerrado de supuestos de admisión de medios de garantía, sino que está abierto a las diversas posibilidades que hemos detallado ampliamente en este trabajo, siempre que cumplan los requisitos formales, y sea jurídica y económicamente adecuada en cuanto a su suficiencia. Por ello, en este caso, el propio apartado décimo del artículo 52 del RGR establece que la aceptación de la garantía como válida requiere que se efectúe en documento administrativo, que se remitirá a los registros públicos, para

60 J. I. Moreno Fernández, La Reforma de la LGT, ed. Lex Nova, 1996, pp. 285 y ss. 
la constancia o fehaciencia de su contenido. Resaltando una vez más la necesidad de una constitución formal o documental de su extensión, para su válida eficacia.

\section{GARANTÍAS POR ACTOS Y CONVENIOS URBANÍSTICOS}

La actividad de carácter urbanístico, tanto en su componente de planificación como de ejecución, es una de las competencias más características de los entes locales, por ello, no podemos dejar de comentar en este trabajo las peculiaridades que su actual régimen legal exige, en la presentación y formalización de determinadas garantías, que son necesarias en la gestión de dicha actividad. En todo caso, de forma previa, debemos apuntar las dificultades actuales, a la hora de analizar cualquier norma aplicable en esta área de la legislación local, por una parte, por la denominada «jibarización» del Derecho urbanístico estatal, en palabras de R. PARADA VÁZQUEZ ${ }^{61}$, debido a la reducción del mismo, tras la Sentencia del Tribunal Constitucional de 20 de marzo de 1997, así como a lo que T. R. FERnÁndeZ Rodríguez ${ }^{62}$ denomina, como «Derecho urbanístico comparado», por la variedad de legislación, que existe, de las 17 Comunidades Autónomas, con competencias casi plenas en esta materia, y que han ido formando un agregado de normas autonómicas variadas y heterogéneas, complicando el estudio y análisis de los aspectos legales, dentro del urbanismo actual y, por supuesto, del objeto del presente estudio.

Aun con las dificultades apuntadas y, en cierta medida, de forma temeraria, vamos a adentrarnos levemente en dicha materia, a los efectos de intentar determinar qué tipo de medios de garantías son los de uso más frecuente en este apartado de la actuación local y dada la imposibilidad de agotar dicho campo por la variedad de legislaciones autonómicas y lo complejo de la vigencia, pervivencia o derogación de las normas estatales. En principio, intentaremos realizar un comentario sobre las exigencias contenidas en las normas del Texto Refundido de la Ley del Suelo del 92 (en adelante TRLS/1992), en la parte que se considere vigente, tras la antedicha Sentencia del Tribunal Constitucional, así como del contenido en sus reglamentos de desarrollo. Entendiendo que algunas citaciones y menciones a los mismos pueden considerarse derogadas, en algunas Comunidades Autónomas, o bien han sido sustituidas por leyes y normas

61 R. Parada Vázquez, Derecho Administrativo, III Parte, Ed. Marcial Pons, 1998, pp. 365 y ss.

62 T. R. Fernández Rodríguez, Manual de derecho urbanístico, ed. El Consultor, Madrid, 1999. 
propias, pero que, dada la finalidad del presente estudio, pueden resultar ilustrativas, como antecedentes de las legislaciones vigentes, y como complemento de las que se comentan de las diferentes Comunidades, si bien, por motivos de espacio exclusivamente, citaremos el contenido de la Ley de Disciplina de la Comunidad de Madrid de 1984, así como la refundición de los textos vigentes en la Comunidad Autónoma de Cataluña, por el Decreto Legislativo 1/1990.

En principio, la legislación urbanística suele precisar la presentación de garantías o cauciones de forma previa, en algunas autorizaciones, necesarias para la ejecución del desarrollo urbanístico. Sometiendo habitualmente a licencia previa el derecho de edificar, a urbanizar, al aprovechamiento urbanístico, etc. Un ejemplo lo vemos en el artículo 40.1.B) del Reglamento de Gestión Urbanística (RGU), que establece la necesidad de fianza para conceder la facultad de edificar en unos supuestos especiales, según la situación del propietario. Otro caso lo presenta el artículo 219 del mismo reglamento, sobre aprobación de programas de actuación especial, siendo requisito necesario, para su aprobación, la presentación de garantías exigibles para responder tanto de la formación del programa, como de la ejecución del mismo.

Existen, de otra parte, dentro de esta legislación otras imposiciones y exigencias de caución, y son aquellas que hacen relación a la naturaleza convenida en la resolución de actos y actuaciones de esta naturaleza, y que dado el desarrollo ad nauseam que actualmente presentan los convenios urbanísticos, en las corporaciones locales, como comenta PARADA VÁZQUEZ ${ }^{63}$, esta circunstancia va provocando de forma pareja que cada vez más se desarrolle la imperiosa necesidad y, en ciertos casos, obligatoriedad de presentar garantía o caución suficiente, que asegure el cumplimiento de lo convenido, y ello porque, en muchas de estas actuaciones, lo acordado no deja de presentar o implicar, por parte de la actuación municipal, el ejercicio de potestades administrativas, que podrían verse lesionadas y con ello, el interés público, quedando de esta forma salvaguardados de posibilidades no deseadas, pero posibles, de tal suerte que pasamos a analizar ambos apartados.

63 R. Parada Vázquez, Derecho Administrativo, III Parte, ed. Marcial Pons, 1998, pp. 350 y ss. 


\section{A) Garantías necesarias en la Gestión de Autorizaciones Urbanísticas}

En cuanto a las necesidades de prestar garantía o caución en los procedimientos y actos de gestión urbanística, tanto de planeamiento, de gestión o autorización propiamente dicha, como de disciplina, éstas tienen un arraigo histórico en la normativa tipo. Así, por ejemplo, el artículo 105 del TRLS/1992 establecía la necesidad de garantías para la admisión y aprobación de iniciativas particulares. La concreción del tipo de medios que pueden presentarse, para este determinado tipo de autorizaciones, la encontramos, por ejemplo, en el artículo 46 del Reglamento de Planeamiento (RP), donde su letra c) establece que los planes parciales de iniciativa privada deberán contener, entre otros documentos, garantías del exacto cumplimiento de dichos compromisos, por importe del 6 por 100 del coste que resulta, para la implantación de los servicios y ejecución de las obras de urbanización, pudiendo presentarse las mismas en metálico, en valores públicos o mediante aval bancario. En este aspecto, es clara la limitación tipológica, pues, a pesar del condicional «podrán», la enumeración es limitativa o cerrada, en comparación a otras, que incluyen cláusulas residuales, como veremos en el caso de ciertas CC.AA.

Las legislaciones autonómicas han ido recogiendo esta necesidad, si bien técnicamente de forma más correcta, y, así, se han determinado y precisado las condiciones de las mismas. En el caso de la Comunidad Autónoma de Madrid, por ejemplo, la Ley 4/1984, en su artículo 5, establece la necesidad de prestar caución o garantía del 3 y 6 por 100, para «asegurar el cumplimiento de los compromisos obligaciones y deberes de los promotores de planes parciales, respondiendo las mismas del cumplimiento de los deberes y obligaciones impuestas, de los compromisos contraídos e incluso de las multas que pudieran imponerse». Para, en su apartado segundo, determinar que las garantías que podrán constituirse a elección del promotor son exclusivamente las que lo hagan, en Metálico, en Deuda Pública del Estado, Comunidad Autónoma o Entidad Local, que se entregarán en prenda en las Tesorerías correspondientes, y en Avales de Banco, debidamente registrado o de Caja de Ahorros, o Entidad de seguros. También admite esta Ley la constitución de garantías mediante $\mathrm{Hi}$ poteca u otra fórmula distinta de las anteriores, pero de eficacia similar y siempre que resulte bastante, a juicio de la Administración.

Las normas, de la Comunidad Autónoma de Cataluña, contenidas en el texto refundido 1/1990, establecen que en los planes parciales presentados a iniciativa del particular, con el fin de garantizar la obligación de 
urbanizar deberá constituirse garantía suficiente, equivalente al 12 por 100 del presupuesto, y que ésta podrá hacerlo de las siguientes formas: en Metálico, mediante Hipoteca de los terrenos susceptibles de edificación, dentro del sector objeto de urbanización (ésta deberá posponerse automáticamente a cualquier otra que se constituya para garantizar los gastos de urbanización), en Títulos de deuda pública del Estado, la Generalidad o cualquier ente local, mediante Aval de Banco oficial o privado, debidamente registrado, Caja de Ahorros o por Entidad de Seguros (en la actualidad, seguro de caución), por último, la legislación también admite la posibilidad de garantía mediante hipoteca sobre terrenos, dentro del propio término municipal, que sean susceptibles de edificación privada, y situados fuera del sector objeto de urbanización, de un valor suficiente para cubrir el importe de la garantía.

Como resumen vemos que la legislación autonómica estudiada, en síntesis, ha establecido, tanto en el ámbito legal, como reglamentario, una mayor precisión en la determinación, requisitos y formalidades que deben reunir las cauciones y garantías que deban presentarse por exigencias legales, abriendo en cierta medida la tipología a nuevas formas, sobre las inicialmente establecidas, con carácter exclusivo, en el texto refundido del 92, si bien, como hemos comprobado, tampoco puede decirse que sean admisibles todo tipo de garantías, sin limitaciones, dado que solamente lo serán a criterio de la Administración, por lo que un particular no puede exigir la constitución de un tipo concreto de garantía, y su admisión requiere una «manifiesta» suficiencia y eficacia en su constitución, tramitación y, en su caso, ejecución.

\section{B) Garantías necesarias y convenientes en los convenios urbanísticos}

En este apartado vamos a realizar un breve resumen de los mismos, por la importancia que actualmente tienen en la gestión del urbanismo local, dada la diversidad de ejecuciones llevadas a cabo mediante convenios. Su fundamento lo encuentra en la naturaleza contractual o convenida de los mismos, éste sería el caso de PAREJO ALFONSO, quien en concreto ${ }^{64}$ considera que los mismos pueden ser desarrollo del artículo 88 de la Ley 30/1992, y para BUSTILLO Y CUERNO ${ }^{65}$ más en concreto, en el artículo 111 del Texto Refundido de Régimen Local, RD 781/1986, así como

\footnotetext{
${ }^{64}$ L. Parejo Alfonso y otros, Manual de derecho administrativo, ed. Ariel, 1998, pp. 752 y ss.

${ }^{65}$ Bustillo Bolado y Cuerno Llata, Los Convenios urbanisticos entre las Administraciones Locales y los particulares, ed. Aranzadi, 1997.
} 
en la propia LCAP, y en concreto en su artículo 5.2.b), para aquellos convenios, que podemos denominar típicos, dentro de la Ley Suelo del 92, y que por tanto se regularían, conforme al artículo 8 de la TRLCAP, por lo que es necesario que entre las cláusulas administrativas de los mismos consten la garantías provisionales y definitivas, que se deban exigir, o bien cuando se consideran convenios «atípicos», en el artículo 3.1.d) de la misma ley, pero siéndole entonces de aplicación el artículo 9 de ésta, sobre contratos privados de la Administración. En cualquier caso, no todos consideran tan acertada, la aplicación de la naturaleza contractual de los mismos; así, PARADA VÁZQUEZ, en cierta medida, estima indisponible contractualmente el ejercicio de ciertas potestades urbanísticas ${ }^{66}$.

En este punto y a los únicos efectos de la cuestión aquí tratada, sobre las garantías que deben acompañar en su caso, a los convenios, como caución, tanto de la correcta ejecución de un contrato, si así se interpreta, como si lo que se conviene pudiera implicar el ejercicio de poderes exorbitantes por parte de la Administración. Vamos, con R. BustiLlo y R. CUERNO ${ }^{67}$, a resumir los posibles modelos de éstos, distinguiendo los convenios denominados típicos, que se rigen por su carácter netamente administrativo, primero por las normas administrativas propias de naturaleza especial o urbanística y seguidamente por la legislación de contratos de las Administraciones públicas. Mientras que los convenios o contratos atípicos se regirán, a falta de normas propias, por las generales del Derecho administrativo, y en concreto las contractuales, en cuanto a su preparación y adjudicación, según la teoría de los actos separables y por las de Derecho común o civil, en cuanto a sus efectos y extinción. Y a los propósitos aquí estudiados, establece el artículo 36.1, último párrafo, del TRLCAP, que en los contratos privados será facultativo para el órgano de contratación la exigencia de la garantía definitiva. La diferenciación, como vemos, ha dejado de tener importancia a la hora de establecer qué garantías son las que pueden legalmente aportarse en este tipo de actuaciones del área urbanística. Dado que únicamente se admitirán por imposición legal aquellas que administrativamente se exigen en sus normas concretas y si no se determinaran, se regirán por las generales, y que son las establecidas como únicas para la contratación administrativa en la Ley de Contratos de las Administraciones Públicas.

A) CONVENIOS TÍPICOS, o con soporte legal previamente establecido entre la Administración y los particulares, que se pueden encontrar

66 R. Parada VÁzquez, Derecho administrativo, III Parte, Ed. Marcial Pons, 1998, pp. 350 y ss.

67 Bustillo Bolado y Cuerno Llata, Los convenios urbanísticos..., op. cit. 
en la legislación urbanística, los que en su cumplimiento pueden o deben aportar a algún tipo de garantía o caución, que asegure su cumplimiento futuro, dentro sólo de las comprendidas en los artículos 35 y 36 del TRLCAP, así encontramos, entre otros, los siguientes:

1. Convenios para formulación y ejecución de programas de actuación urbanística (arts. 177 a 184 TRLS/1992).

2. Convenios expropiatorios (arts. 217 TRLS/1992 y 208 RGU/1992).

3. Convenios para la gestión indirecta de la expropiaciones urbanísticas (art. 213 TRLS/1992).

4. Convenios para la constitución de servidumbres (art. 211 TRLS/1992)

5. Convenios sobre los gastos de urbanización (art. 155.2 TRLS/1992).

6. Convenios para la transferencia de excesos de aprovechamiento urbanístico (art. 151.4 TRLS/1992).

7. Convenios para el aplazamiento de los gastos de urbanización en el sistema de cooperación (art. 163.3 TRLS y fundamentalmente a lo que aquí nos interesa, $190 \mathrm{RGU} / 1978$ ).

8. Convenios para instrumentar la intervención mediadora de la Administración en las transferencias de aprovechamiento urbanísticos en actuaciones sistemáticas (art. 194 TRLS/1992).

9. Convenios sobre condiciones de realización y mantenimiento de las urbanizaciones en los planes y proyectos redactados por los particulares [art. 105.2.d), TRLS/1992 y 46 RP/1978]. Como el caso anterior, los proyectos redactados por los particulares incluirán los datos y compromisos necesarios para la adecuada ejecución de los mismos, con detalle concreto de las garantías para el exacto cumplimiento. En concreto la letra c) del artículo 46 del RP establece:

«Las garantías del exacto cumplimiento de dichos compromisos por importe del 6 por 100 del coste que resulta para la implantación de los servicios y ejecución de las obras de urbanización según la evaluación del propio plan. Las garantías podrán prestarse en metálico, en valores públicos o mediante aval bancario.»

Vemos en este caso que la legislación establece la necesidad de prestar garantía del exacto cumplimiento de las obligaciones y el tipo de las que 
deben ser admitidas, y ciertamente presentan un carácter más limitado, por ejemplo, que las necesarias en la Ley de Contratos del Estado.

La importancia del incumplimiento del requisito de aportar las garantías suficientes es resaltado por la doctrina, por todos, GONZÁleZ PÉREZ 68, para quien esta carencia es causa suficiente, para la no aprobación del convenio, también resaltadas, en Sentencias del TS, como la de 23 de abril de 1975 (RJA 2634) o la más reciente, de 5 de febrero de 1992 (RJA 2246).

B. CONVENIOS ATÍPICOS. En este caso la atipicidad jurídica de los mismos nace de la realidad social, sin encontrar ubicación en los tipos de la legislación urbanística, por ello pueden existir tantos formas como convenios o contratos se suscriban, sin que se puedan hacer una sistemática de tipos preestablecidos legalmente. En cuanto a las clasificaciones, con BUSTILlO y CUERNO ${ }^{69}$ podemos distinguir entre aquellos que responden a los términos y condiciones de la gestión y ejecución del planeamiento en vigor, de aquellos otros que su objeto y contenido son las posibles modificaciones del mismo.

Estos últimos son los que responden, a grosso modo, a la finalidad contractual de la permuta civil (do ut facies), por lo que, dada la peculiaridad del objeto, en muchas ocasiones, no se han admitido por el Tribunal Supremo cuando ha llegado a su jurisdicción. Se pueden citar, a título de ejemplo, los convenios para el realojo de vecinos en operaciones de reforma interior.

Entendemos que, en estos casos, las garantías que se deban presentar ante la administración local, por la atipicidad legal de dichos convenios no deben constreñirse primeramente a las establecidas en la Ley de Contratos de las Administraciones Públicas, puesto que, aunque en ciertos casos los mismos pueden incluir obligaciones de cumplimiento o ejercicio de potestades de carácter público o administrativo, su inclusión supone siempre pactos ciertamente anómalos, al existir para ello instrumentos legales suficientes, sin tener que acudir a figuras contractuales atípicas. Pero el hecho concreto es que estas construcciones jurídicas pueden abrir las posibilidades a otras figuras establecidas en legislaciones sectoriales, como son las de carácter patrimonial, por lo que, en esos casos, de manera supletoria y a falta de reglamentación expresa, se deben aplicar únicamente las normas contractuales ya vistas sobre garantías.

\footnotetext{
68 Jesús GonzÁlez Pérez, Comentarios a la Ley del Suelo, ed. Civitas, 1993, pp. 760 y ss.

69 Bustillo Bolado y Cuerno Llata, Los convenios urbanísticos..., op. cit.
} 


\section{ALGUNAS CONCLUSIONES}

1. ${ }^{\circ} \quad$ La complejidad e importancia de las garantías que se deben aportar, por interesados y terceros, en los procedimientos administrativos del régimen local, no han sido suficientemente valoradas en la normativa actual. A diferencia, por ejemplo, de la reglamentación precedente, donde de forma ordenada se establecía un «corpus jurídico homogéneo» sobre el contenido, efectos y fines de las mismas.

2. ${ }^{\circ} \quad$ Dicha importancia, por la extensión y desarrollo, del campo de actuación de los entes locales, ya no sólo se circunscribe a las tradicionales fianzas contractuales o de garantía del pago, en reclamaciones de terceros ante la entidad local, sino que se debe incluir un campo más vasto, como el de los aplazamientos de ingresos de todo tipo, los convenios y pactos urbanísticos y aquellos otros actos administrativos, que requieren un cumplimiento diferido o condicionado, exigiendo, por tanto, unas medidas cautelares, que aseguren dicha finalidad en el futuro.

3..$^{\circ} \quad$ Por su parte, la complejidad en este aspecto concreto de las garantías viene determinada, de un parte, por el aumento de nuevas figuras provenientes en su mayoría del Derecho mercantil y de la Contabilidad Financiera y que van siendo paulatinamente asimiladas por la acción administrativa. Y de otra, por el extremado formalismo que su válida constitución demanda, dados los riesgos de falencia y envilecimiento que los mismos encierran, y que están en amplia contradicción con las características de agilidad y celeridad que su finalidad requiere.

4. ${ }^{\circ} \quad$ Entre los nuevos medios introducidos en el régimen local, son novedosas las figuras del seguro de caución, y la prenda de valores mediante anotaciones en cuenta, con una ordenación sustantiva, así como el más tradicional del aval bancario, también con una configuración reglamentaria propia. Pero ello sin obviar las posibilidades que presentan los medios clásicos, como pueden ser la fianza, entre las garantías personales, y la Hipoteca y la Prenda, en sus distintas clases, entre las denominadas como garantías reales.

5..$^{\circ}$ En otros casos, las formas ya conocidas, a su vez, han generado posibilidades y opciones derivadas, como puede ser el caso de la prenda de créditos, que con ciertas formalidades y limitaciones pudiera ser admitida como medio de garantía en algunos supuestos, si bien, ante la facilidad, extensión, economía, y efectividad que en la actualidad presentan el aval bancario y el seguro de caución, como garantías independientes, y 
que no podemos dejar de resaltar y valorar positivamente dichas posibilidades están hoy todavía ciertamente limitadas.

6. ${ }^{\circ} \quad$ Las ventajas comentadas del aval y del seguro de caución proceden, según hemos podido ver, de la inclusión de cláusulas denominadas de ejecución «al primer requerimiento o la primera demanda» y que, conforme a la más clásica doctrina y jurisprudencia, suponen más una acumulación de deudores, que refuerza solidariamente su cumplimiento, que una garantía tipo tradicional y subsidiaria, y ello por el carácter solidario expreso que implica su inclusión.

7. ${ }^{\circ} \quad$ En cualquier caso, según lo visto en el campo de la administración local no todas las posibilidades de garantías estudiadas se pueden admitir siempre en todos los supuestos. En principio, en este aspecto, son las garantías a presentar ante la hacienda local las que admiten un más amplio número de posibilidades de constitución, fundamentalmente por el tipo de derechos que garantiza. Donde tanto en reclamaciones, como en aplazamientos, se podrán admitir legalmente todas las estudiadas en este trabajo, si bien, por las características intrínsecas y efectos propios de algunas de ella, no resultan, adecuadas en la tramitación dentro de los procedimientos locales, como, por ejemplo, para la resolución del recurso de reposición de la LHL, a la vista del perentorio plazo que su resolución requiere y que impide garantías que impliquen amplios plazos para su valoración y formalización.

8. ${ }^{\circ} \quad$ Por su parte, la Ley de Contratos de las Administraciones Públicas es más prudente en las formas admisibles, ello motivado principalmente por las finalidades que persigue, por lo que únicamente admite unos supuestos tasados, tanto para garantías provisionales, como definitivas. Si bien, tanto el aval bancario, como el seguro de caución, son los instrumentos más usuales o frecuentes dentro de la actividad económica, y por ello los de más fácil aplicación. Siendo además las garantías establecidas en dicha ley las que de forma supletoria deberán aplicarse en el régimen local, por reenvío de las leyes y reglamentos, en el supuesto de que no tengan señalado un régimen jurídico concreto.

9. Las garantías necesarias en el ámbito del Derecho urbanístico actual, dentro de la división efectuada en el presente trabajo, tienen una complejísima variedad derivada de la vigencia de la legislación anterior, en parte derogada, y la nueva de carácter autonómico, no bien conocida, y dependiendo, además, de los fines concretos a los que deba ser aplicada (planeamiento, gestión, disciplina, etc.), si bien, como hemos visto a lo largo de este trabajo, las que se manifiestan por la legislación suelen ha- 
cer referencia a los medios de garantía con carácter limitado, metálico, avales, prenda de valores, por lo que, supletoriamente en esta materia, así como en la de convenios urbanísticos, deberán admitirse a falta de normativa propia aplicable, exclusivamente las formas o medios recogidos en la Ley de Contratos de las Administraciones Públicas.

10. $\quad$ En cualquier caso, la apreciación de la suficiencia tanto jurídica como económica de una garantía es una valoración a realizar, dada la complejidad actual que algunas de ellas conllevan, por la entidad local, previos los informes técnicos correspondientes. Por ello, dentro de las posibilidades marcadas legalmente, la elección del tipo concreto es siempre una alternativa del contribuyente, usuario, contratista, etc., pero la admisión como válida y suficiente lo será siempre a juicio o criterio de la entidad local, sin que sea obligatorio por su parte la admisión de una garantía concreta a instancia de un particular, si bien los criterios empleados en la valoración y calificación de la misma, que no pueden ser discrecionales, siempre serán controlables por los Tribunales de Justicia de lo Contencioso, como cualquier otro acto administrativo. 